OPEN ACCESS

Edited by:

Pietro Giusti,

University of Padova,

Italy

Reviewed by:

Luigia Trabace, University of Foggia,

Italy

Antonio Carlos Pinheiro De Oliveira, Federal University of Minas Gerais,

Brazil

*Correspondence:

Corinne Joffre

corinne.joffre@inra.fr

Specialty section:

This article was submitted to

Neuropharmacology,

a section of the journal

Frontiers in Pharmacology

Received: 21 March 2019

Accepted: 12 August 2019

Published: 13 September 2019

Citation:

Joffre C, Rey C and Layé S (2019) N-3 Polyunsaturated Fatty Acids and the Resolution of Neuroinflammation.

Front. Pharmacol. 10:1022.

doi: 10.3389/fphar.2019.01022

\section{N-3 Polyunsaturated Fatty Acids and the Resolution of Neuroinflammation}

\author{
Corinne Joffre ${ }^{1,2 *}$, Charlotte Rey ${ }^{1,2,3}$ and Sophie Layé ${ }^{1,2}$ \\ ${ }^{1}$ INRA, Nutrition et Neurobiologie Intégrée, UMR 1286, Bordeaux, France, 2 Université de Bordeaux 2, Bordeaux, France, \\ ${ }^{3}$ ITERG, Nutrition Health and Lipid Biochemistry Department, Canéjan, France
}

In the past few decades, as a result of their anti-inflammatory properties, n-3 long chain polyunsaturated fatty acids (n-3 LC-PUFAs), have gained greater importance in the regulation of inflammation, especially in the central nervous system (in this case known as neuroinflammation). If sustained, neuroinflammation is a common denominator of neurological disorders, including Alzheimer's disease and major depression, and of aging. Hence, limiting neuroinflammation is a real strategy for neuroinflammatory disease therapy and treatment. Recent data show that n-3 LC-PUFAs exert anti-inflammatory properties in part through the synthesis of specialized pro-resolving mediators (SPMs) such as resolvins, maresins and protectins. These SPMs are crucially involved in the resolution of inflammation. They could be good candidates to resolve brain inflammation and to contribute to neuroprotective functions and could lead to novel therapeutics for brain inflammatory diseases. This review presents an overview 1) of brain n-3 LC-PUFAs as precursors of SPMs with an emphasis on the effect of n-3 PUFAs on neuroinflammation, 2) of the formation and action of SPMs in the brain and their biological roles, and the possible regulation of their synthesis by environmental factors such as inflammation and nutrition and, in particular, PUFA consumption.

Keywords: n-3 long-chain PUFAs, docosahexaenoic acid, eicosapentaenoic acid, specialized pro-resolving mediators, nutrition, neuroinflammation, resolvins

\section{INTRODUCTION}

Inflammation is a critical process in host defense, facilitating tissue repair, regeneration and maintenance of homeostasis. However, if uncontrolled, it becomes a chronic low-grade inflammation that is characterized by the production of pro-inflammatory cytokines and adipokines leading to tissue damage and loss of function (López-Vicario et al., 2016). This chronic low-grade inflammation is observed in many chronic pathologies including neurodegenerative diseases and also in aging. Hence it becomes a significant public health concern and constitutes a financial burden that impacts millions worldwide (Serhan, 2017b). It is thus of importance to find treatments that ensure resolution of inflammation in a specific time-limited manner. Nutrition has gained importance in recent years since nutriments such as n-3 polyunsaturated fatty acids (PUFAs) have anti-inflammatory properties (Calder, 2016; Calder et al., 2017). They exert their effect in part through their conversion into bioactive lipid mediators called specialized pro-resolving mediators (SPMs) that underlie most of the beneficial effects attributed to their precursors (Serhan, 2014; López-Vicario et al., 2016). Recently, attention has been paid to these derivatives in the regulation of neuroinflammation. In this review, we present an overview of brain n-3 PUFAs and their effect on neuroinflammation and of the formation and mechanisms of the action of SPMs in the brain. 


\section{BRAIN N-3 PUFAS AS PRECURSORS OF SPMs}

\section{Brain n-3 PUFAs}

The brain contains high levels of PUFAs (25-30\%) that are mainly docosahexaenoic acid (DHA, n-3 PUFA) (12-14\% of total fatty acids) and arachidonic acid (AA, n-6 PUFA) (8-10\% of total fatty acids) (Carrie et al., 2000; Xiao et al., 2005; McNamara and Carlson, 2006; Little et al., 2007; Chung et al., 2008; Joffre et al., 2016). There are regional differences: the hippocampus and prefrontal cortex contain the highest DHA content whereas the hypothalamus has the lowest (Carrie et al., 2000; Xiao et al., 2005; Joffre et al., 2016). There are also cellular differences: astrocytes, oligodendrocytes, and microglial cells (representing respectively $70 \%, 10-15 \%$ and $10-15 \%$ of brain glial cells; Renaud et al., 2015) contain DHA in different proportions. DHA represents $10-12 \%$ in astrocytes, $5 \%$ in the oligodendrocytes and up to $2 \%$ in microglial cells (Bourre et al., 1984; Rey et al., 2018). Neurons cannot synthesize long-chain PUFAs (LC-PUFAs) but can incorporate them in their membranes: DHA represents $8.3 \%$ of the total fatty acids in neurons (Bourre et al., 1984).

Numerous studies have discussed the transport of DHA through the blood-brain barrier (BBB). DHA enters the brain as unesterified DHA that is the major pool supplying the brain with DHA. However, the precise mechanisms of entry are still not fully described. Some transporters facilitate the uptake of DHA into the brain: fatty acid transport proteins (FATPs), fatty acid translocase (CD36) and major facilitator superfamily domain containing 2A (MFSD2A) (Chouinard-Watkins and Bazinet, 2018). Fernandez et al. (2018) recently reported that a member of the long-chain acyl-CoA synthetase (ACSL) family, ACSL6, is also involved in brain DHA uptake but its role has yet to be determined (Fernandez et al., 2018).

This brain fatty acid composition can be affected by environmental factors such as nutrition, something to which individuals are continuously exposed. Indeed, the PUFA content in all brain structures is strongly impacted by the PUFAs present in the diet (Alashmali et al., 2016; Joffre et al., 2016). A diet rich in n-3 PUFAs (DHA found in fish or its precursor, alpha-linolenic acid, found in vegetable oil) increases brain DHA in rodents (Hiratsuka et al., 2009; de Theije et al., 2015; Skorve et al., 2015; Kitson et al., 2016). However, DHA supplementation is more effective than alpha-linolenic supplementation in increasing the DHA content in the brain (Lacombe et al., 2017; Rey et al., 2019). In rodents, DHA supplementation from 16 weeks to 16 months or from 20 to 22 months of age compensates a DHA decrease due to aging (Little et al., 2007; Labrousse et al., 2012; Bascoul- Colombo et al., 2016). On the other hand, a diet deficient in n-3 PUFAs decreases brain DHA in all brain structures, with the hippocampus, containing most DHA, being the most affected and the hypothalamus the least affected (Delpech et al., 2015b; Joffre et al., 2016; Manduca et al., 2017).

Studies from Broadhurst and Crawford suggest that the amount of DHA incorporated into the brain depends on the complexity of the brain structure and on behavior development (Crawford et al., 1999; Broadhurst et al., 2002). A decrease in brain DHA induced by a deficient diet during gestation and lactation can be reversed by 2-month DHA supplementation at weaning (Orr et al., 2013). The organism also adapts its metabolism to an n-3 PUFA deficiency condition: the half-life of DHA increases in the brain to reduce its loss (Rapoport et al., 2007) and the activity of the enzymes responsible for DHA conversion, the $\Delta 6$ desaturase and elongase, is increased in the liver (Cho et al., 1999; Wang et al., 2005; Igarashi et al., 2007). Brain cells are also impacted by dietary PUFA supply. An n-3 PUFA deficient diet decreases DHA in astrocytes, neurons and oligodendrocytes (Bourre et al., 1984) whereas n-3 PUFA supplementation increases DHA levels in glial cells (Bowen and Clandinin, 2005; Destaillats et al., 2010). Moreover, we recently showed that the fatty acid composition of the microglial cells is also modulated by n-3 PUFA dietary intake during the gestation/lactation period. Maternal n-3 LC-PUFA dietary supplementation during gestation and lactation increases the DHA level in the offspring's microglia at P21 as compared with a maternal diet that contains equilibrated levels of n-6 and n-3 PUFA precursors (Rey et al., 2018). Interestingly, maternal n-3 PUFA deficiency does not impact the DHA level suggesting that microglial cells are protected from n-3 PUFA deficiency (Rey et al., 2018).

\section{n-3 PUFAs as Regulators of Neuroinflammation}

n-3 PUFAs have powerful anti-inflammatory properties (Calder, 2005). They play an important role in the regulation of the synthesis and release of pro-inflammatory mediators (Delpech et al., 2015b; Hanisch and Kettenmann, 2007; Cunningham and Sanderson, 2008; Yirmiya and Goshen, 2011; Pascual et al., 2012). Pro-inflammatory factors include interleukin-1 beta (IL-1 $\beta$ ), interleukin-6 (IL-6) and tumor necrosis factor alpha (TNF- $\alpha$ ) and play a role in neuronal plasticity (Delpech et al., 2015b; Yirmiya and Goshen, 2011). If sustained, uncontrolled inflammation can lead to neuronal damage that is involved in many neuronal pathologies (Blais and Rivest, 2003; Layé, 2010; Solito and Sastre, 2012). Hence, limiting the inflammation and enhancing the resolution of inflammation is of great interest.

\section{Evidence in Humans}

In humans, the anti-inflammatory properties of n-3 PUFAs were first identified in epidemiological studies in Eskimos that consume a lot of n-3 LC-PUFAs from eating fish (Dyerberg and Bang, 1979; Kromann and Green, 1980; Simopoulos, 2008). Clinical studies have highlighted the beneficial effect of $n-3$ LC-PUFAs in chronic inflammatory and autoimmune diseases. Indeed, fish oil supplementation decreases pro-inflammatory cytokine expression, such as IL- $1 \beta$ in blood monocytes, and improves the symptoms of patients suffering from rheumatoid arthritis (Kremer et al., 1990; James et al., 1997; Kremer, 2000) or multiple sclerosis (Stewart and Bowling, 2005; WeinstockGuttman et al., 2005). Moreover, DHA supply significantly decreases the circulating inflammatory markers and the oxidative stress (Freund-Levi et al., 2006; Kiecolt-Glaser et al., 2012). DHA supply for several months also improves the working 
and long-term memories in patients with moderate cognitive alterations (Freund-Levi et al., 2006; Lee et al., 2013).

\section{Evidence in Animals}

In animals, numerous studies have demonstrated the antiinflammatory properties of $\mathrm{n}-3$ PUFAs in the brain. In lipopolysaccharide (LPS)-, or IL-1 $\beta$-, induced inflammation models, dietary n-3 LC-PUFA supplementation in adulthood prevents LPS-induced hippocampal increase of pro-inflammatory cytokines IL-1 $\beta$ and TNF- $\alpha$ in rats and mice (Orr et al., 2013; Dehkordi et al., 2015; Rey et al., 2019). A dietary supply in eicosapentaenoic acid (EPA) decreases the production of LPSinduced pro-inflammatory cytokines IL- $1 \beta$, IL- 6 and TNF- $\alpha$ in the hippocampus and increases the production of antiinflammatory cytokines IL-10 and IL-4 in both rats (Kavanagh et al., 2004; Lonergan et al., 2004; Dong et al., 2017) and mice (Shi et al., 2016). This modification is associated with a decrease in the phosphorylation of $\mathrm{c}$-Jun and $\mathrm{c}$-Jun $\mathrm{N}$-terminal kinase proteins and in nuclear factor-kappa $\mathrm{B}(\mathrm{NF \kappa B})$ that regulate inflammation (Lonergan et al., 2004; Shi et al., 2016). EPA dietary supply attenuates the activation of microglial cells and astrocytes triggered by an intracerebral IL- $1 \beta$ administration and increases the production of IL-10 in the hippocampus in rats (Song and Horrobin, 2004; Song et al., 2008; Dong et al., 2017). Following dietary DHA supplementation, there is an increase of DHA in the phospholipid and free fatty acid fractions. However, only the unesterified DHA is necessary to attenuate neuroinflammation. Nevertheless, the DHA phospholipid pool is an important source of unesterified DHA (Orr et al., 2013). On the contrary, in mice, an n-3 PUFA deficiency from the first day of gestation to weaning increases the expression of pro-inflammatory markers in the hippocampus and an alteration in the motility and the phenotype of microglial cells and alters synaptic plasticity (Lafourcade et al., 2011; Madore et al., 2014; Thomazeau et al., 2017). Using the model of intraperitoneal (ip) injection of LPS, we showed that IL-6 expression is strongly induced in n-3 PUFA-deficient mice whereas sickness behavior is down-regulated via the impairment of IL-6 signaling in the brain (Mingam et al., 2008). Moreover, when the deficiency continues in adulthood, it alters GABAergic, dopaminergic and cholinergic neurotransmission (Zimmer et al., 2000; Aid et al., 2003; Chalon, 2006; Larrieu et al., 2014) and anxiety-related, depressive-like behaviors that can be compared with autistic behavior in adults (Mingam et al., 2008; Larrieu et al., 2012; Larrieu et al., 2014; Hughes et al., 2016; Manduca et al., 2017). Following ip injection of LPS, n-3 PUFAdeficient mice display altered hippocampal synaptic plasticity that likely contributes to spatial memory impairment and higher glucocorticoid levels (Delpech et al., 2015b). On the contrary, an n-3 PUFA dietary supply improves emotional behavior alteration and memory deficit in rats (Song and Horrobin, 2004; Song et al., 2008; Dong et al., 2017), restores social and memory performance altered in autism models and improves depressive symptoms in both mice (Pietropaolo et al., 2014; Madore et al., 2016; Weiser et al., 2016) and rats (Bove et al., 2018; Morgese et al., 2018). Of note, n-3 LC-PUFA dietary supplementation attenuates depressive symptoms in depressed patients presenting inflammation (McNamara, 2015; Rapaport et al., 2016; Larrieu and Layé, 2018; Layé et al., 2018). This protective effect seems to be linked to EPA which could target microglia to reduce neuroinflammation (Bazinet et al., 2019). n-3 LC-PUFAs could also modulate neuroinflammation through their effect on the HPA axis (Larrieu et al., 2014; Hughes et al., 2016; Larrieu and Layé, 2018). With Alzheimer's disease, $\beta$-amyloid triggers depressive symptoms through neuroinflammatory processes that could be improved by dietary n-3 PUFAs (Bove et al., 2018; Morgese et al., 2018). Altogether these data reinforce the importance of n-3 PUFAs as regulators of inflammation and associated depressive symptoms.

Another way to modulate neuroinflammation is to administer n-3 PUFAs directly into the brain or peripherally. Indeed, a 24-hour intracerebroventriculary (icv) DHA brain infusion attenuates hippocampal neuroinflammation initiated by icv LPS in mice (Orr et al., 2013). In a mouse model of cerebral ischemia, DHA icv administration inhibits NFKB activation and cyclooxygenase-2 (COX-2) expression in the hippocampus (Marcheselli et al., 2003). Moreover, intrathecal injection of DHA decreases microglial activation, mitogen-activated protein kinase (MAPK) phosphorylation and the production of proinflammatory cytokines in the spinal cord of mice ( $\mathrm{Lu}$ et al., 2013). In addition, in a model of traumatic brain injury in rats, n-3 PUFA ip injection attenuates microglial-induced inflammation by inhibiting the NFkB pathway (Chen et al., 2017).

Dietary n-3 LC-PUFA supplementation requires the use of fish oil. However, fish oil may provide confusing factors such as vitamins, for example. Thus, the use of Fat-1 transgenic mice that convert n-6 to n-3 PUFAs through a desaturase from C. elegans is a model that enables the elimination of confusing factors provided by the diet (Kang et al., 2004). Such mice have higher DHA levels in the hippocampus and cortex (Delpech et al., 2015a; Boudrault et al., 2010; Orr et al., 2013). They express less COX-2 (involved in the production of lipid mediators) in the cortex than wild type mice (Boudrault et al., 2010). They are protected against cognitive deficits induced by ip LPS injection through a decrease in neuroinflammation (Orr et al., 2013; Delpech et al., 2015a). This is associated with a decrease in microglial activation (Orr et al., 2013).

\section{Evidence in In Vitro Studies}

In vitro studies have shown that $\mathrm{n}-3$ PUFAs have an inhibitory effect on the production of pro-inflammatory cytokines in microglial cells. Indeed, in the microglial cell line or primary culture microglial cells, DHA prevents LPS-induced NKkB activation and then cytokine production by inhibiting LPS receptor presentation and decreases the oxidative stress, nitric oxide (NO) production and inducible nitric oxide synthase (iNOS) expression (De Smedt-Peyrusse et al., 2008; Lu et al., 2010; Antonietta Ajmone-Cat et al., 2012; Pettit et al., 2013; Chen et al., 2014; Corsi et al., 2015; Fourrier et al., 2017; Inoue et al., 2017;). Moreover, DHA prevents LPS-induced MAPK phosphorylation (MAPK pathway playing essential roles in the expression of inflammatory molecules) and induces peroxisome proliferatoractivated receptor (PPAR)- $\gamma$ nuclear translocation that exerts anti-inflammatory effects (Antonietta Ajmone-Cat et al., 2012). Of interest, EPA also affects the production of TNF- $\alpha$, IL- 6 and 


\section{Acute inflammation \\ Onset of resolution \\ Resolution}

\author{
- $\uparrow$ pro-inflammatory cytokines \\ (IL-1 $\beta$, TNF- $\alpha$, IL-6) \\ 8 \\ $-\uparrow$ pro-inflammatory lipid \\ mediators derived from $A A$ \\ (prostaglandins, thromboxanes, \\ leukotrienes)
}

\section{- $\downarrow$ pro-inflammatory cytokines}

- Bioactive lipid mediator class switch
- $\uparrow$ anti-inflammatory cytokines

(IL-10, TGF- $\beta \ldots$..)

- $\uparrow$ pro-resolutive and anti-

inflammatory mediators

derived from DHA and EPA

FIGURE 1 | Molecular events implicated in inflammation and the resolution of inflammation. AA, arachidonic acid; DHA, docosahexaenoic acid; EPA, eicosapentaenoic acid; IL, interleukin; TGF, transforming growth factor; TNF, tumor necrosis factor.

NO by inhibiting NFkB phosphorylation via sirtuin-1 (SIRT-1) (Moon et al., 2007; Chen et al., 2014; Inoue et al., 2017). It is likely that DHA attenuates the inflammatory response in LPS-activated microglia by remodeling lipid bodies that are dynamic organelles in which DHA is incorporated and by altering their interplay with mitochondria and other associated organelles (Tremblay et al., 2016). In addition, DHA and EPA are able to enhance myelin or amyloid $\beta(A \beta)$ peptide phagocytosis that is associated with a shift in microglial polarization toward the beneficial M2 phenotype and to a decrease in pro-inflammatory cytokine production (Hjorth et al., 2013; Chen et al., 2014).

This modulation of neuroinflammation induced by $n-3$ LC-PUFA supply is attributed, in part, to SPM synthesis (Barden et al., 2016). In the various phases of inflammatory response, prostaglandins, leukotrienes and thromboxane are synthesized first (Figure 1). They permit the propagation of inflammation. They also stimulate the synthesis of SPMs with pro-resolutive properties (Levy et al., 2001; Serhan and Savill, 2005).

\section{n-3 PUFA-Derived SPMs and Their Synthesis Pathway}

Many of the n-3 PUFA-derived immunomodulators that orchestrate the inflammatory response are lipids (Doyle et al., 2018). Some of them are involved in the regulation of inflammation (prostaglandins, thromboxanes, leukotrienes, etc.) and others are implicated in the resolution of inflammation (resolvins, protectins and maresins). There is a temporal shift in the lipid mediator synthesis from the initiation of inflammation to the resolution that allows the formation of different lipid mediators at different times (Figure 1). Here we have focused on SPMs, which are of great interest since they permit a return to homeostasis (Serhan et al., 2015; Sugimoto et al., 2016). Charles N. Serhan first identified these SPMs at the periphery and characterized their anti-inflammatory and pro-resolutive properties (Serhan et al., 2000). SPMs actively orchestrate and finely tune the inflammatory response. They decrease pro-inflammatory cytokines and increase anti-inflammatory cytokines, accelerate the phagocytosis of cellular debris and dead cells without immune suppression. A failure in the resolution of inflammation is detrimental for tissue and contributes to a chronic inflammatory response.

\section{BIOSYNTHESIS AND BIOLOGICAL ROLES OF n-3 PUFA-DERIVED SPMs}

\section{Biosynthesis of $n-3$ PUFA-Derived SPMs}

Free (unesterified) n-3 LC-PUFAs are released from membrane phospholipids through the action of phospholipases A2 (PLA2) in response to stimulation. DHA is hydrolyzed by calcium independent PLA2 (iPLA2) from phospholipids and plasmenylethanolamine-PLA2 from plasmalogens (Farooqui and Horrocks, 2006). After this step, n-3 LC-PUFAs undergo an enzymatic conversion to generate SPMs (Figures 2 and 3).

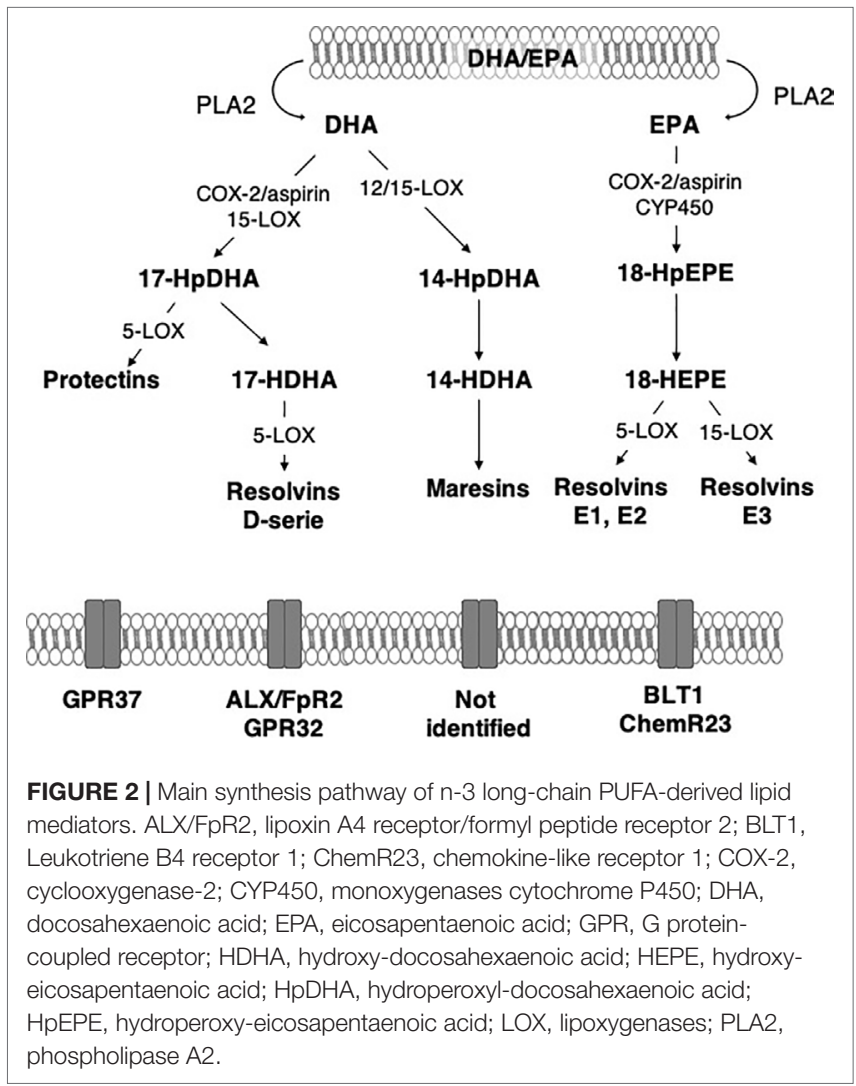



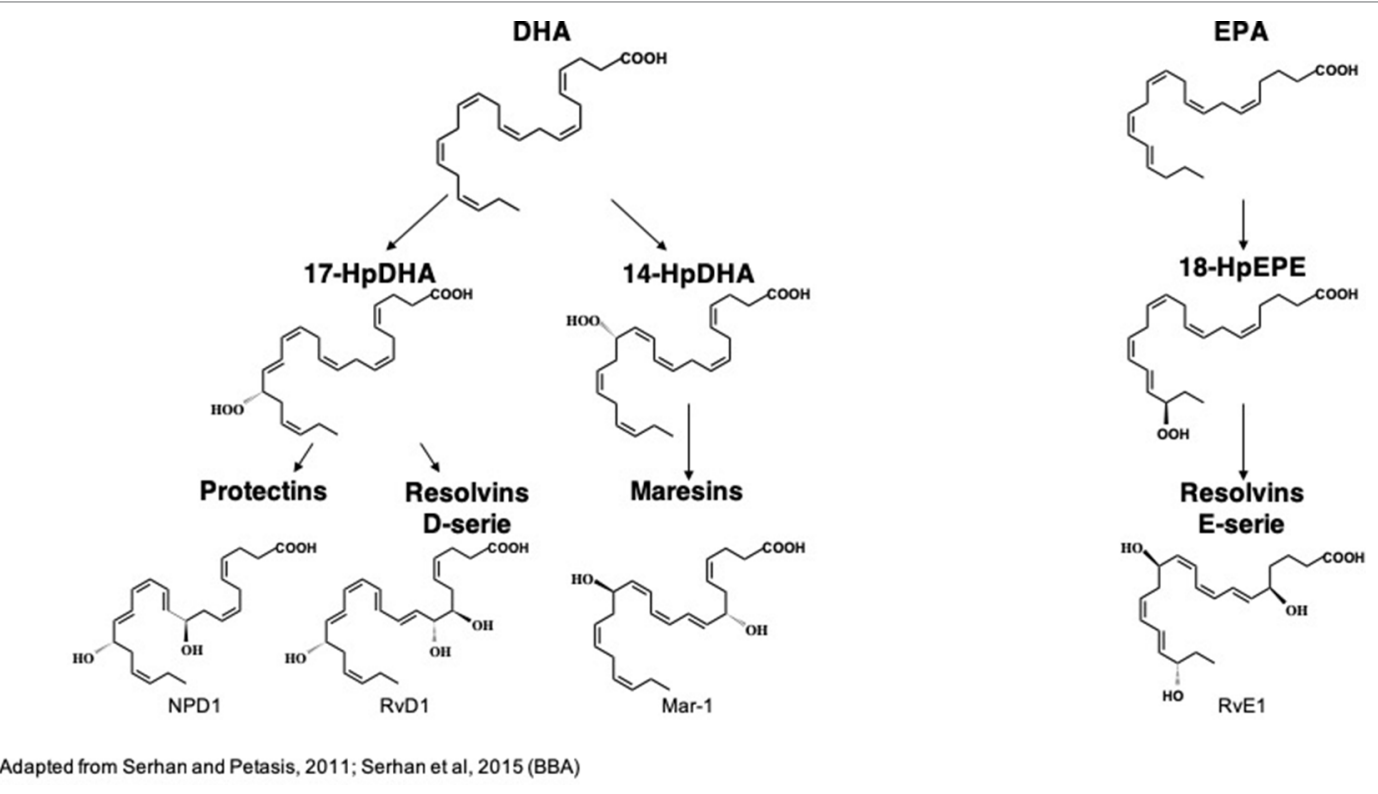

FIGURE 3 | Biochemical structures of the main n-3 long-chain PUFA-derived lipid mediators. DHA, docosahexaenoic acid; EPA, eicosapentaenoic acid; HpDHA, hydroperoxyl-docosahexaenoic acid; HpEPE, hydroperoxy-eicosapentaenoic acid; Mar1, maresin 1; NPD1, neuroproetectin D1; RvD1, resolvin D1; RvE1, resolvin E1. (Serhan and Petasis, 2011; Serhan et al., 2015)

n-3 PUFA-derived SPMs are synthesized mainly from DHA and EPA via COX-2, lipoxygenases (LOX) and CYP450 monoxygenases (CYP450). In the brain, 15-LOX, 12/15LOX and 5-LOX are the most abundant LOX and are widely distributed, suggesting the potential production of SPMs (Shalini et al., 2017). They are expressed in the second step of inflammation in the hippocampus (Czapski et al., 2010; Birnie et al., 2013). 15-LOX is involved in neurodegeneration and neurotoxicity due to the increased oxidative stress it generates in models of Alzheimer's disease (Pratico et al., 2004; Wang et al., 2015) and brain ischemia (Yigitkanli et al., 2017). However, it is also implicated in neuroprotection (Sun et al., 2015). Indeed, it increases the production of 12-HETE and 15-HETE that promote the activation of PPAR $\gamma$ that is neuroprotective through its anti-inflammatory properties. The inhibition of 15-LOX induces hippocampus-dependent cognitive alterations (Shalini et al., 2017). Indeed, it prevented long term potentiation, a major molecular mechanism that describes the strengthening of synapses and underlies learning and memory. Moreover, 15-LOX deletion drastically decreases SPM production in the brain while SPMs also modulate synaptic plasticity (Park et al., 2011; Shalini et al., 2017). In the brain, the inducible COX-2 is activated via an NFkB pathway (Nadjar et al., 2005). COX-2 catalyzes the first step of the synthesis of prostaglandins and thromboxanes derived from n-6 PUFAs that contribute to the initiation of inflammation (Davidson et al., 2001; Salinas et al., 2007; Engstrom et al., 2012). COX-2 also produces hydroxyl fatty acids from DHA in both an aspirin-dependent and aspirinindependent manner (Serhan et al., 2002; Oh et al., 2011; Gabbs et al., 2015; Nebert, 2017). In response to LPS, COX-2 is rapidly expressed in the hippocampus (Czapski et al., 2010; Rey et al., 2019). Inhibition of COX-2 delays resolution of acute inflammation (Schwab et al., 2007). CYP450s play a complex role in inflammation by producing n-6 PUFAderived bioactive mediators such as epoxides that are antiinflammatory in monocytes and macrophages (Bystrom et al., 2011; Fleming, 2011; Nebert et al., 2013; Gilroy et al., 2016).

DHA is the precursor of resolvins D1-6 (RvD1-6), neuroprotectin D1 (NPD1) and maresins 1-2 (Mar1-2) which all have pro-resolutive and anti-inflammatory properties (Spite and Serhan, 2010; Halade et al., 2018). RvD1-6 are synthesized from DHA but RvD1 is the most studied because it has powerful anti-inflammatory and proresolutive properties. DHA is converted into monohydroxy DHA, 17-hydroxy docosahexaenoic acid (17-HDHA) by acetylated COX2, CYP450 and 15-LOX (Barden et al., 2016; Halade et al., 2018) and then into RvD1 by 5-LOX (Sun et al., 2007; Recchiuti, 2013). DHA is also converted into di-hydroxy-DHA, termed protectin D1 (PD1) or neuroprotectin D1 (NPD1) when produced in the central nervous system by 5- and 15-LOX (Hong et al., 2003; Aursnes et al., 2014; Kuda, 2017; Doyle et al., 2018). Acetylated COX-2 permits the synthesis of aspirin-triggered PD1 (AT-PD1) which has powerful protective effects (Bazan et al., 2012). DHA is transformed into Mar 1-2 by 12/15-LOX via the synthesis of 14-HDHA (Serhan et al., 2009; Barden et al., 2016; Halade et al., 2018).

EPA is the precursor of resolvins E1 (RvE1), E2 and E3 that have many biological roles (Serhan et al., 2000; Rey et al., 2016; Halade et al., 2018). It is converted by aspirin-triggered acetylated COX-2 or CYP450 into 18R-hydroxyeicosapentaenoic acid (18R-HEPE), that is transformed into RvE1 or E2 by 5 -LOX (Ohira et al., 2010; Barden et al., 2016) or into RvE3 by 15-LOX (Isobe et al., 2012). 
Little is known concerning the pharmacokinetics and dynamics of oxylipins. They are synthesized in situ, reinforcing the importance of the fatty acid composition of the brain. They are not stored, but produced on demand and they are unstable, being rapidly metabolized.

The structure of all derivatives is highly preserved in the evolution from fish to humans suggesting their great bioactive role in all organ systems. Dysfunction of SPM production can be due to insufficient EPA and DHA supply leading to inadequate production of SPMs or to the polymorphism of the enzymes involved in their synthesis or to a defect in the binding of SPMs to their receptors (Sugimoto et al., 2016). In humans, reduced SPM production is associated with chronicity and the magnitude of persistent inflammation. SPMs have multiple biological roles in the maintenance of homeostasis.

\section{Biological Roles of DHA-Derived SPMs}

In human serum, the DHA-derivatives represent $30.7 \%$ of the identified SPMs (Colas et al., 2014; Serhan et al., 2018). RvD1, PD1 and Mar1 were detected at $30.9 \mathrm{pg} / \mathrm{mL}, 5.6 \mathrm{pg} / \mathrm{mL}$ and 21.2 $\mathrm{pg} / \mathrm{mL}$, respectively. They act in the nanomolar or picomolar range as compared with DHA and EPA acting in the micromolar range (López-Vicario et al., 2016; Clària et al., 2017; Serhan, 2017a; Wang and Colgan, 2017; Rosenthal et al., 2018).

\section{Resolvins}

RvDs have been identified in mice peritoneal exudates (Serhan et al., 2002). They have many properties at the periphery: protection against bacterial infection, prevention of leucocyte infiltration, inhibition of the production of cytokines, etc. (Spite et al., 2009; Serhan and Petasis, 2011; Chiang et al., 2012; Dalli et al., 2013a; Winkler et al., 2016). RvD1 and its precursor metabolites have been detected in the brain.

In vitro, 17-HDHA has been found in glial cells after DHA and inflammatory stimulus (Hong et al., 2003). In vivo, RvD1 has been identified in mouse brain following cerebral ischemia (Marcheselli et al., 2003). Intravenous (iv) DHA injection increases RvD1 levels in rats suggesting the conversion of DHA into RvD1 (Mulik et al., 2016). RvD1 acts through the lipoxin A4 receptor/formyl peptide receptor 2 (ALX/Fpr2) in rodents and the G protein coupling receptor 32 (GPR32) in humans (Recchiuti, 2013) in the picomolar range but induces biological effects in the nanomolar range (Sun et al., 2007; Krishnamoorthy et al., 2010). An overexpression of ALX/Fpr2 or GPR32 increases in phagocytosis by macrophages whereas their deletion decreases the phagocytosis response (Perretti et al., 2002; Krishnamoorthy et al., 2010; Cooray et al., 2013). RvD1 regulates the expression of specific micro-RNA ( $\mathrm{miR}$ ) to control the intensity and the length of inflammation via the regulation of target genes such as inflammatory cytokine genes (Fredman and Serhan, 2011; Recchiuti et al., 2011; Rey et al., 2016; Bisicchia et al., 2018). RvD1 increases the expression of miR-21, miR-146b and miR219 and decreases the expression of miR-208a in macrophages and peritoneal exudates in mice (Recchiuti et al., 2011; Krishnamoorthy et al., 2012). RvD1 modulates miR-155, miR146, miR-21 and miR-219 in microglial cells (Rey et al., 2016).
These miRs have different biological roles: $\mathrm{miR}-21$ is essential to the production of anti-inflammatory cytokine IL-10, miR-146 regulates the transcription of cytokines, chemokines and their receptor, miR-219 decreases the transcription of TNF- $\alpha$ and miR208a regulates the activation of NFkB (Recchiuti et al., 2011).

RvD1 controls the inflammatory response in many animal models via its anti-inflammatory and pro-resolutive properties. In rats, endogenous $\mathrm{RvD} 1$ levels decrease at the beginning of inflammation and then increase during the resolution phase (Sun et al., 2014). Recent studies describe the anti-inflammatory properties of RvD1 in microglia and astrocyte cell cultures (Abdelmoaty et al., 2013; Li et al., 2014; Rey et al., 2016). Indeed, in BV2 microglia cell culture, RvD1 promotes the IL-4-induced M2 phenotype (Li et al., 2014) and inhibits LPS-induced proinflammatory cytokines (Rey et al., 2016). In astrocyte cell culture, RvD1 attenuates LPS-induced TNF- $\alpha$ (Abdelmoaty et al., 2013). In vivo, in a model of remote damage, Bisicchia et al. recently show in rats that RvD1 promotes functional recovery and reduces neuroinflammation via miRs (Bisicchia et al., 2018).

\section{Biological Roles of RvD1 in Humans}

The effect of RvD1 has been studied in patients suffering from Alzheimer's disease. This pathology is characterized by an increase in microglial activation and in pro-inflammatory cytokine production in the brain (Griffin et al., 1989; Cagnin et al., 2001). Interestingly, RvD1 levels in the cerebrospinal fluid are positively correlated with the enhancement of cognitive functions of patients with dementia (Wang et al., 2015). Indeed, RvD1 may be involved in $\mathrm{A} \beta$ phagocytosis. This has been shown in vitro in macrophages isolated from Alzheimer's patients (Mizwicki et al., 2013; Famenini et al., 2017). Thus the decrease in RvD1 levels in Alzheimer patients' brains could contribute to the evolution of the disease.

\section{Biological Roles of RvD1 in Rodents}

RvD1 attenuates the pro-inflammatory status in the central nervous system. Indeed, an intrathecal injection of 17R-HDHA decreases TNF- $\alpha$ release in the spinal cord in rats (Abdelmoaty et al., 2013). Orr et al. show that icv injection of 17S-HDHA into mice decreases the expression of hippocampal pro-inflammatory cytokines IL- $1 \beta$ and TNF- $\alpha$ induced by LPS acute icv injection (Orr et al., 2013). However, these authors detected NPD1 but did not detect RvD1, suggesting that the effect of 17S-HDHA was rather due to the conversion of 17S-HDHA into NPD1. RvD1 is also able to stimulate phagocytosis in macrophages (Rossi et al., 2015). Indeed, DHA and RvD1 induce the polarization of macrophages toward an M2 phagocytic phenotype in mice (Titos et al., 2011).

Studies have highlighted the protective role of RvD1 in the occurrence of cognitive deficits. Terrando et al. showed that an ip injection of 17-HDHA restores transmission and synaptic plasticity and prevents astrogliosis and cognitive decline in a systemic inflammation model in mice (Terrando et al., 2013). Conversely, an inhibition of 15-LOX, associated with a decrease in RvD1, alters synaptic plasticity and working memory as demonstrated in rats (Shalini et al., 2017). RvD1 plays also a role during the recovery phase following cerebral 
ischemia. Indeed, the precursor of 17-HDHA, 17-hydroperoxy docosahexaenoic acid (17-HpDHA), accumulates in the hippocampus of mice (Marcheselli et al., 2003). An ip chronic administration of 17R-HDHA synthesized by acetylated COX2, prevents cognitive deficits and attenuates motor disorders but doesn't ameliorate microglial activation and sleep quality in mice (Harrison et al., 2015). Moreover, Fat-1 mice that have more brain n-3 LC-PUFAs, have higher hippocampus RvD1 levels, associated with less cognitive deficits, a better neuronal survival, a decrease in astrocyte and microglial activation and a reduction in pro-inflammatory status following brain ischemia (Luo et al., 2014; Delpech et al., 2015a).

Studies have also highlighted the protective role of resolvins in the depressive-like behavior in rodents. Some of them have been recently reported by Furuyashiki et al. (Furuyashiki et al., 2019). An icv injection of RvD1, D2, E1, E2, or E3 significantly decreases LPS-induced depressive-like behavior in mice (Deyama et al., 2017; Deyama et al., 2018a; Deyama et al., 2018b). Moreover, the occurrence of depressive-like behavior associated with pain can also be prevented by an intrathecal injection of 17R-HDHA that is associated with the decrease of pain perception and a restoration of dopamine and glutamate levels in the brain both in rats (Abdelmoaty et al., 2013) and mice (Klein et al., 2014). RvD1 and D2 have also positive effects in chronic mild stressinduced depression and in post-myocardial infarct depression in rats (Gilbert et al., 2014) and mice (Ishikawa et al., 2017).

\section{Biological Roles of RvD1 in In Vitro Models}

The effects of RvD1 were tested on different brain cells. In microglial cells, RvD1 potentiates the effect of the antiinflammatory cytokine IL-4 in the activation of M2 phenotype of microglia (Li et al., 2014). Moreover, we showed that RvD1 decreases LPS-induced pro-inflammatory cytokines (TNF-a, IL- 6 and IL-1 $\beta$ ) gene expression in microglial BV2 cells via the modulation of miRs (Rey et al., 2016). This suggests its proresolutive activity in microglia. In astrocytes, RvD1 decreases TNF- $\alpha$ release induced by LPS injection (Abdelmoaty et al., 2013). In neurons from spinal nods, RvD1 increases neurite outgrowth (Shevalye et al., 2015). All these studies suggest that RvD1 can play a central role in the regulation of neuroinflammatory pathologies.

Other $\mathrm{D}$ resolvins have been identified in rodent brain: RvD2, RvD4 and RvD5 (Orr et al., 2013; Hashimoto et al., 2015; Winkler et al., 2016). RvD2 limits the activation of microglial cells and inhibits the TLR4/NFKB pathway (Tian et al., 2015). Moreover, chronic intrathecal $\mathrm{RvD} 2$ injection prevents the behavioral alterations induced by LPS central injection (Tian et al., 2015). It also prevents depressive-like behavior induced by ip LPS injection by regulating mammalian target of rapamycin complex 1 (mTORC1) complex (Deyama et al., 2017). RvD5 level is decreased in the brain of Alzheimer's disease patients but its role has not yet been identified (Zhu et al., 2016).

\section{Neuroprotectin}

Di-hydroxy-DHA termed protection D1 (PD1) has been identified in blood, peritoneal neutrophils and neuroprotectin D1 (NPD1) in the brain in response to zymosan in mice (Hong et al., 2003). Marcheselli et al. have measured NPD1 production in mice hippocampus following brain ischemia (Marcheselli et al., 2003). One receptor for NPD1 has recently been identified as GPR37 (Qu and Caterina, 2018). NPD1 inhibits the oxidative stress in retinal epithelial cells and stimulates their proliferation (Bazan, 2009; Calandria and Bazan, 2010). NPD1 is also able to inhibit neovascularization via microglial cell ramification in mice (Sheets et al., 2013). In the central nervous system of mice, the NPD1 level greatly increases in the hippocampus following brain ischemia or acute central LPS injection (Marcheselli et al., 2003; Orr et al., 2013). Hence, NPD1 limits neutrophil infiltration, inhibits NFKB and then decreases pro-inflammatory gene expression (Marcheselli et al., 2003; Bazan et al., 2012; Yao et al., 2013). NPD1 levels decrease in the hippocampus of Alzheimer's disease patients (Lukiw et al., 2005). It plays a role in cellular survival via anti-apoptotic protein induction and attenuates pro-inflammatory responses following $A \beta$ exposure via NFkB regulation (Lukiw et al., 2005; Bazan, 2008; Asatryan and Bazan, 2017).

\section{Maresins}

Mar1 has been identified in mice peritoneal macrophages (Dalli et al., 2013b; Serhan et al., 2009). Its receptor has not been identified yet (Zhu et al., 2016). Mar1 is involved in the resolution of inflammation, prevents neutrophil infiltration, and increases the phagocytosis of apoptotic neutrophils by macrophages in a peritonitis murine model (Serhan et al., 2009). In a murine model of colitis, Mar1 decreases the expression of pro-inflammatory cytokines by inhibiting the NFKB pathway and activating the M2 phenotype in macrophages (Marcon et al., 2013). Mar1 and its precursor 14-HDHA have recently been identified in the hippocampus of mice (Orr et al., 2013). In post-mortem brain of Alzheimer's disease patients, the Mar1 level is decreased (Zhu et al., 2016). In this pathology, its role is to stimulate $\mathrm{A} \beta$ plaque phagocytosis by microglial cells and to decrease inflammatory marker levels. Hence, Mar1 may play an important role in the pathogenesis of Alzheimer's disease (Zhu et al., 2016). In cerebral ischemia in mice, Mar1 icv injection decreases inflammation and mitochondrial damage and also reduces neurological deficits via activation of SIRT-1 signaling (Xian et al., 2016; Xian et al., 2019). After spinal cord injury in mice, iv injection of Mar1 promotes resolution of inflammation (reducing pro-inflammatory cytokines, silencing pro-inflammatory signaling cascades and enhancing the M2 repair macrophage phenotype) and functional recovery (Francos-Quijorna et al., 2017). Mar1 also decreases in vitro neuronal death (Zhu et al., 2016).

\section{Biological Roles of EPA-Derived SPMs}

RvE1, and its precursor 18-HEPE, have been detected in the hippocampus of rats (Chen et al., 2011) and mice (Orr et al., 2013; Siegert et al., 2017). In human serum, the EPA-derivatives represent $25.9 \%$ of the identified SPMs (Colas et al., 2014; Serhan et al., 2018).

RvE1 has been initially identified in mouse exudates (Serhan et al., 2000). RvE1 directly binds to its receptor ChemR23 or 
CMKLR1 (chemokine-like receptor 1) (Ohira et al., 2010). It is also a partial agonist of LTB4 receptor (BLT1) (Arita et al., 2007). In the central nervous system, ChemR23 has been identified in the prefrontal cortex, hippocampus and brainstem (Guo et al., 2012), in microglial cells (Graham et al., 2009; Rey et al., 2016) and in neurons (Xu et al., 2010). It is highly expressed in neurons, in microglial cells and in astrocytes in the post-mortem hippocampus of Alzheimer's patient brain (Wang et al., 2015). This increase could be due to a compensatory mechanism to counter-balance the decrease in RvE1 in such patients (Wang et al., 2015). In vitro, RvE1 plays also a direct role in microglial cells by inhibiting microglial activation and pro-inflammatory cytokine release (Xu et al., 2013; Rey et al., 2016). RvE1 and its precursor, 18R-HEPE, exert anti-inflammatory and anti-apoptotic properties (Hecker et al., 2018). Indeed, they restore mitochondrial dysfunction induced by inflammation in mononuclear blood cells. In vivo, RvE1 modulates the inflammatory profile and microglial activation in mice (Xu et al., 2013; Harrison et al., 2015). Intraperitoneal injection of RvE1 also modulates inflammation (by reducing Il-1 $\beta$, Il-6 and IL-10 levels in the prefrontal cortex) and decreases the measures of $A \beta$ pathology in a murine model of Alzheimer's disease (Kantarci et al., 2018). RvE1 and RvE2 centrally administered also reduce the LPS-induced depressive-like behavior through ChemR23 in mice (Deyama et al., 2018b). RvE1, a total agonist of ChemR23, is more effective than RvE2, which is only a partial agonist of this receptor (Serhan and Chiang, 2013).

\section{REGULATION OF THE n-3 PUFA-DERIVED SPMs}

Resolution of inflammation is an active process involving the regulation of the synthesis of numerous mediators in a tightly coordinated manner. The balance between n-3 PUFA-derived SPMs and the pro-inflammatory mediators determines the duration of the inflammatory response and the timing of resolution (Fredman et al., 2017).

\section{Regulation of the n-3 PUFA-Derived SPMs by PUFA Consumption}

We have previously shown that PUFA consumption leads to modifications in PUFA levels in the brain. The PUFA derivative levels and their biosynthetic enzyme expression also depend on dietary PUFAs.

SPM levels in peripheral organs and the brain are modulated by different dietary supplies of PUFAs (Figure 4). In humans supplemented with 2.4g/day of n-3 LC-PUFAs for 3 weeks (EPA+DHA), SPM levels are generally found to be between 20 and $200 \mathrm{pg} / \mathrm{mL}$ (Mas et al., 2012). A shorter supplementation period (5 days) also increased DHA- and EPA- derived SPMs in plasma, especially 18-HEPE, RvE1, 17- and 14-HDHA (Barden et al., 2014). In another study, supplementing patients with a higher fish oil supplement (17.6g/day EPA+DHA) for $24 \mathrm{~h}$, only PD1 is detected in the plasma and this increases from 1.0-1.2 pg/mL to 2.7-4.1 pg/mL (Skarke et al., 2015; Barden

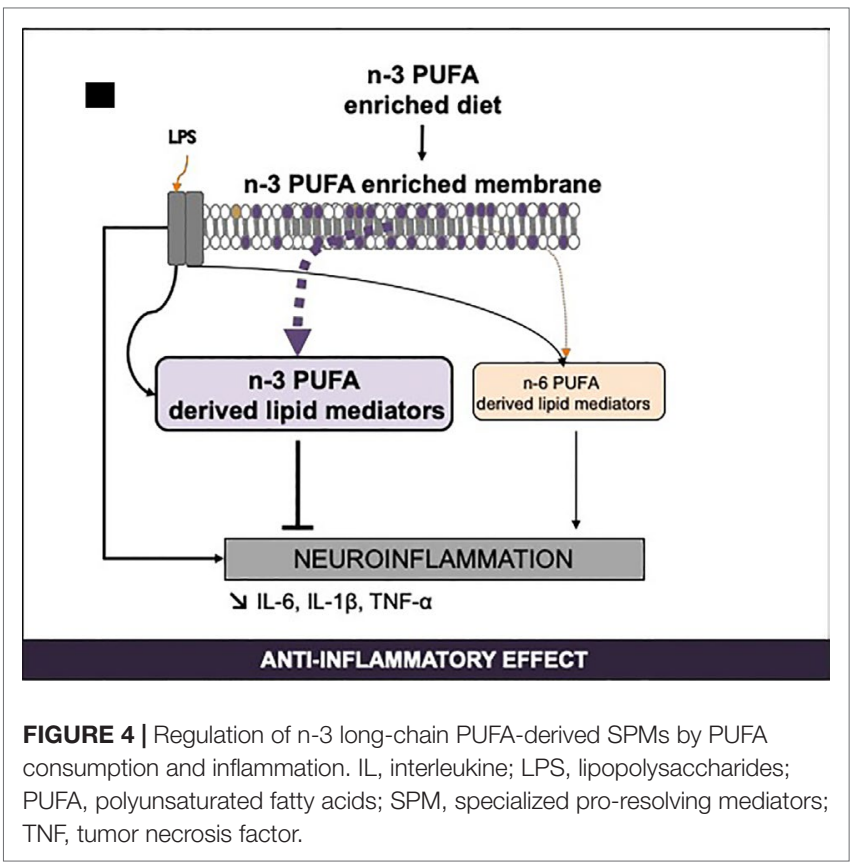

et al., 2016). These differences in SPM levels in human plasma could be due to differences in study design, dose, duration of n-3 fatty acid supplementation and patient characteristics, etc. (Barden et al., 2016; Chiang and Serhan, 2017). Moreover, dietary supplementation in DHA $(1.7 \mathrm{~g} / \mathrm{j})$ and EPA $(0.6 \mathrm{~g} / \mathrm{j})$ for 6 months increased the RvD1 released by blood mononuclear cells in Alzheimer's disease patients as compared with controls (Wang et al., 2015). Results from intervention studies show that EPA and DHA dietary supplementation increases EPA- and DHAderived oxylipins although with high inter-individual variances (Ostermann et al., 2017).

In animals, a 3-week fish oil supplementation in arthritic mice increases synthesis of n-3 PUFA-derived SPMs associated with a diminished production of pro-inflammatory mediators (Norling et al., 2016). n-3 PUFA dietary supplementation (140 mg $\mathrm{EPA}+110 \mathrm{mg}$ DHA $/ \mathrm{kg}$ animal) in aged rats for 10 weeks enhances the production of lipid mediators derived from DHA and EPA in the cerebral cortex (Hashimoto et al., 2015). DHA and EPA supply also decreases the n-6 PUFA-derived metabolites (which are mainly pro-inflammatory) and increases the n-3 PUFAderived metabolites in the plasma and at the periphery both in mice (Balvers et al., 2012; Lazic et al., 2014) and rats (Hashimoto et al., 2015). A diet enriched with fish oil (containing 9\% EPA + 9\% DHA) for 8 weeks in mice increases plasmatic RvD1 (Shevalye et al., 2015). In Fat-1 mice, brain EPA increase is accompanied by an increase in EPA-derived HEPEs (Siegert et al., 2017). Conversely, an n-6 PUFA dietary supply from weaning to 15 weeks of age increases the n-6 PUFA metabolites and decreases the EPA-derived metabolites in the cortex and the plasma of rats (Taha et al., 2016). Recently, we showed that, in mice, n-3 LC-PUFA supplementation from weaning for 2 months induces n-3 LC-PUFA enrichment in the hippocampus and subsequently an increase in n-3 PUFA-derived SPMs and a decrease in n-6 
PUFA-derived mediators (Rey et al., 2019). Moreover, in response to LPS, n-3 LC-PUFA-deficient mice present a pro-inflammatory lipid mediator profile whereas n-3 LC-PUFA-supplemented mice display an anti-inflammatory profile in the hippocampus (Rey et al., 2019). Indeed, the consumption of n-3 LC-PUFAs increases the EPA and DHA derivatives. Hashimoto et al. found the same in the cortex of aged rats (Hashimoto et al., 2015). These results differ from those of Trépanier et al. who found that, in a model of Fat-1 mice, a greater increase in brain DHA induced by dietary supply has no effect on the resolution of inflammation after an icv LPS injection (Trépanier et al., 2018).

SPM production is also finely tuned by the regulation of the enzymes in their biosynthesis pathway. A 15-week n-3 PUFA-deficient diet increases the COX-2 expression in the prefrontal cortex of rats, suggesting an increase in AA-derived pro-inflammatory mediator levels (Rao et al., 2007). Conversely, a 15-week n-6 PUFA-deficient diet decreases brain COX-2 expression in rats (Kim et al., 2011). Interestingly, Taha et al. showed that rats fed on an n-6 PUFA-deficient diet for 15 weeks are protected from an increase in COX-2 observed in LPS-treated n-3 PUFA-deficient animals (Taha et al., 2017). However, we showed that 2 months' n-3 LC-PUFA dietary supplementation was not sufficient to modulate COX-2 expression in the brain of mice (Rey et al., 2019). An n-3 LC-PUFA diet increases 15-LOX expression in the hippocampus without changes in the 5-LOX expression (Gabbs et al., 2015). The increase in 15-LOX in the brain has also been described following a 15-week n-6 PUFA-deficient diet in rats (Kim et al., 2011). 15-LOX is responsible for many n-6 and n-3 PUFA derivatives. Those synthesized from AA drastically decrease, and those produced from DHA increase, following a diet enriched in n-3 PUFAs in both mice and rats (Ostermann et al., 2017; Shalini et al., 2017; Rey et al., 2019).

Results on 15-LOX functions on inflammation regulation are conflicting. 15-LOX was initially described as deleterious in neurodegenerative pathologies because it increased the oxidative stress and neuronal degeneration (Pratico et al., 2004; Chinnici et al., 2007; Di Meco et al., 2014; Wang et al., 2015; Yigitkanli et al., 2017). It alters the mitochondrial function of neurons and then induces neuronal death (Pallast et al., 2009). However, recent studies demonstrate the protective role of 15-LOX, particularly in cognition. An increase in its expression is associated with a better working memory (Sun et al., 2015; Shalini et al., 2017). Moreover, an increase in 15-LOX expression during cerebral ischemia is essential for the recovery of neurological functions after the ischemic event (Wang et al., 2017). These results suggest that 15-LOX has a beneficial role in acute inflammation (ischemia, LPS) and is deleterious in chronic inflammation (neurodegenerative pathologies). SPM production is also partly regulated by the availability of free PUFAs that are their precursors. Indeed, PLA2 activity also depends on PUFA dietary supply. An n-6 PUFA-deficient diet increases the iPLA2 that is responsible for the release of DHA from the membranes and a decrease in calcium sensitive cytosolic PLA2 (cPLA2) associated with the hydrolysis of AA from the membranes (Kim et al., 2011).

Lipid nutrition, to which people are exposed throughout their lives, seems to play a major role in the synthesis of bioactive SPMs.

\section{Regulation of the n-3 PUFA-Derived SPMs by Inflammation}

Numerous studies have highlighted that inflammation modulates lipid mediator synthesis at the periphery and in the brain (Figure 4).

In humans, Wang et al. showed that the RvD1 level in the cerebrospinal fluid (CSF) of Alzheimer's disease patients is positively correlated with cognitive function (Wang et al., 2015). Moreover, 15-LOX was decreased in the CSF suggesting an alteration of the resolution of inflammation in Alzheimer's patients.

In rats, brain ischemia increases the production of 5 of mono-, di- and tri-hydroxy-DHA derivatives (Farias et al., 2008; Hennebelle et al., 2017). However, LPS icv injection does not impact the RvD1 level (Rosenberger et al., 2004; Taha et al., 2017). We have recently shown that, in mice, ip LPS injection modifies the n-6 PUFA derivative profile but not n-3 LC-PUFA derivatives (Rey et al., 2019).

In vitro, most studies have been performed on peripheral immune cells. The lipid mediator profile in rodent neutrophils and macrophages changes with macrophage phenotype M1 or M2, or with the inflammatory stimulus in neutrophils (Dieter et al., 2002). Indeed, M2 macrophages produce more D resolvins, protectins and maresins and less AA-derived pro-inflammatory mediators than M1 macrophages (Dalli and Serhan, 2012).

Inflammation more drastically alters the expression of biosynthetic enzymes than an n-3 LC-PUFA dietary supply. In rats, traumatic brain injury increases the COX-2, 5-LOX, 15-LOX and CYP450 expression in the hippocampus and cortex, suggesting an alteration of all lipid mediator biosynthesis pathways (Birnie et al., 2013). LPS also regulates the expression of these enzymes. An icv LPS injection increases COX-2 expression and activity in the brain in mice (Rey et al., 2019) and rats. Moreover, in in vitro human monocytes and dendritic cells, antiinflammatory cytokines IL-4 or IL-13 increase the production of 15-LOX and decrease the production of 5-LOX (Nassar et al., 1994; Spanbroek et al., 2001).

Neuroinflammation also modifies SPM receptor expression. Indeed, we show that LPS increases significantly the expression of RvD1 and RvE1 receptors (ALX/Fpr2 and ChemR23, respectively) in BV-2 microglial cells (Rey et al., 2016). The increase in ALX/Fpr2 expression was also detected in monocytes, in the hippocampus and in the cortex and in microglial cells in response to an inflammatory stimulus (Krishnamoorthy et al., 2010; Wang et al., 2011; Wang et al., 2015; Guo et al., 2016). Then, inflammation activates the SPM signaling pathway in the brain to regulate the inflammatory response.

\section{HUMAN TRANSLATION}

Several possibilities can be considered to translate the findings described above and then attenuate the inflammatory tone, amplitude and duration of inflammation. The first one is to increase the local production of n-3 LC-PUFA-derived SPMs. We see that dietary means is a good way to modulate the level of the fatty acids from which they are synthesized and then to modify their synthesis. The SPM profile synthesized by 
each individual could be responsible for the differences in the effects of n-3 PUFA obtained in humans. SPM profiles should be established in patients with different acute and chronic inflammatory pathologies, and in mice under the same conditions to find markers of neuroinflammation in the plasma that can be transposed to humans. Thanks to new technologies in liquid chromatography mass spectrometry (LC-MS/ MS), specific mediators produced during physiological and non-physiological conditions should be identified, allowing patient stratification according to disease severity. It could be interesting to determine an individual metabolomic profile to define personalized nutrition (n-3 PUFAs and doses) allowing an increase of n-3 PUFA-derived SPMs in the target tissue. Indeed, there are individual differences in diets and in n-3 PUFA supplementation and also in nutrient metabolism and biological responses to food/nutrients. The aim of personalized nutrition is to increase health using nutrition by delivering specific personalized intervention suited to each individual based on the individual's nutritional phenotype, metabolic profile, and environmental factors in order to prevent and treat chronic disease. Personalized nutrition can also be applied to healthy people. It is nowadays accessible because of a better understanding of the mechanisms of the effect of nutrition on health and also because of the progress in technologies enabling the identification of specific markers. Personalized nutrition has already shown its efficacy, especially in the Food4Me study involving $>1600$ participants from 7 European countries and in a systematic review and meta-analysis showing a greater efficacy of personalized nutrition in changing diet than a conventional approach (Celis-Morales et al., 2018).

The second possibility for taking advantage of research on the resolution of inflammation is to administer exogenous SPMs. Serhan defines a new concept of resolutive pharmacology targeting the development of SPM analogs, resistant to local

\section{REFERENCES}

Abdelmoaty, S., Wigerblad, G., Bas, D. B., Codeluppi, S., Fernandez-Zafra, T., El-Awady el, S., et al. (2013). Spinal actions of lipoxin A4 and 17(R)-resolvin D1 attenuate inflammation-induced mechanical hypersensitivity and spinal TNF release. PLoS One 8, e75543. doi: 10.1371/journal.pone.0075543

Aid, S., Vancassel, S., Poumes-Ballihaut, C., Chalon, S., Guesnet, P., and Lavialle, M. (2003). Effect of a diet-induced n-3 PUFA depletion on cholinergic parameters in the rat hippocampus. J. Lipid Res. 44, 1545-1551. doi: 10.1194/ jlr.M300079-JLR200

Alashmali, S. M., Hopperton, K. E., and Bazinet, R. P. (2016). Lowering dietary n-6 polyunsaturated fatty acids: interaction with brain arachidonic and docosahexaenoic acids. Curr. Opin. Lipidol. 27, 54-66. doi: 10.1097/ MOL.0000000000000255

Antonietta Ajmone-Cat, M., Lavinia Salvatori, M., De Simone, R., Mancini, M., Biagioni, S., Bernardo, A., et al. (2012). Docosahexaenoic acid modulates inflammatory and antineurogenic functions of activated microglial cells. J. Neurosci. Res. 90, 575-587. doi: 10.1002/jnr.22783

Ariel, A., and Serhan, C. N. (2007). Resolvins and protectins in the termination program of acute inflammation. Trends Immunol. 28, 176-183. doi: 10.1016/j. it.2007.02.007

Arita, M., Ohira, T., Sun, Y. P., Elangovan, S., Chiang, N., and Serhan, C. N. (2007). Resolvin E1 selectively interacts with leukotriene B4 receptor BLT1 and inactivation, to stimulate natural circuits of resolution (Chiang and Serhan, 2017). The objective of this new therapeutic pathway is to administer these analogs in association with classical therapy in order to decrease the doses, thus limiting the secondary effects. A clinical trial has reported for the first time the efficacy of an RvE1 analog in patients with dry eye symptoms (Resolvyx Pharmaceuticals). These encouraging results should be extended to the use of such molecules to treat other inflammatory diseases.

\section{CONCLUSION}

In the investigation of new anti-inflammatory treatments without the secondary effects of traditional therapy, SPMs are promising therapeutic compounds: they are of natural origin and are active at low concentrations (nM) as compared with their precursor $(\mu \mathrm{M})$ (Ariel and Serhan, 2007; Bannenberg and Serhan, 2010). SPMs are detectable in the brain and their level can be modulated by dietary supplementation. They have potent anti-inflammatory and pro-resolutive properties and we confirm the main role of nutrition as an environmental factor that greatly influences the inflammatory response. It is important to determine if inflammatory pathologies are due to unresolved inflammation, attributed to a decrease in n-3 LC-PUFA dietary intake leading to a decrease in SPM levels, to an enzyme or receptor polymorphism, to a de-regulation of SPM receptors or to a decrease in their expression. We should also determine if these mechanisms could be restored by n-3 LC-PUFA or SPM analog administration.

\section{AUTHOR CONTRIBUTIONS}

All authors (CJ, CR, SL) contributed to the writing of the manuscript.

ChemR23 to regulate inflammation. J. Immunol. 178, 3912-3917. doi: 10.4049/ jimmunol.178.6.3912

Asatryan, A., and Bazan, N. G. (2017). Molecular mechanisms of signaling via the docosanoid neuroprotectin D1 for cellular homeostasis and neuroprotection. J. Biol. Chem. 292, 12390-12397. doi: 10.1074/jbc.R117.783076

Aursnes, M., Tungen, J. E., Vik, A., Colas, R., Cheng, C.-Y. C., Dalli, J., et al. (2014). Total synthesis of the lipid mediator PD1n-3 DPA: configurational assignments and anti-inflammatory and pro-resolving actions. J. Nat. Prod. 77, 910-916. doi: $10.1021 / \mathrm{np} 4009865$

Balvers, M. G., Verhoeckx, K. C., Bijlsma, S., Rubingh, C. M., Meijerink, J., Wortelboer, H. M., et al. (2012). Fish oil and inflammatory status alter the n-3 to $\mathrm{n}-6$ balance of the endocannabinoid and oxylipin metabolomes in mouse plasma and tissues. Metabolomics 8, 1130-1147. doi: 10.1007/s11306-012-0421-9

Bannenberg, G., and Serhan, C. N. (2010). Specialized pro-resolving lipid mediators in the inflammatory response: an update. Biochim. Biophys. Acta 1801, 1260-1273. doi: 10.1016/j.bbalip.2010.08.002

Barden, A. E., Mas, E., and Mori, T. A. (2016). n-3 Fatty acid supplementation and proresolving mediators of inflammation. Curr. Opin. Lipidol. 27, 26-32. doi: 10.1097/MOL.0000000000000262

Barden, A., Mas, E., Croft, K. D., Phillips, M., and Mori, T. A. (2014). Shortterm n-3 fatty acid supplementation but not aspirin increases plasma proresolving mediators of inflammation. J. Lipid Res. 55, 2401-2407. doi: 10.1194/jlr.M045583 
Bascoul-Colombo, C., Guschina, I. A., Maskrey, B. H., Good, M., O’Donnell, V. B., and Harwood, J. L. (2016). Dietary DHA supplementation causes selective changes in phospholipids from different brain regions in both wild type mice and the Tg2576 mouse model of Alzheimer's disease. Biochim. Biophys. Acta 1861, 524-537. doi: 10.1016/j.bbalip.2016.03.005

Bazan, N. G. (2008). Neurotrophins induce neuroprotective signaling in the retinal pigment epithelial cell by activating the synthesis of the anti-inflammatory and anti-apoptotic neuroprotectin D1. Adv. Exp. Med. Biol. 613, 39-44. doi: 10.1007/978-0-387-74904-4_3

Bazan, N. G. (2009). Cellular and molecular events mediated by docosahexaenoic acid-derived neuroprotectin D1 signaling in photoreceptor cell survival and brain protection. Prostaglandins Leukot. Essent. Fatty Acids 81, 205-211. doi: 10.1016/j.plefa.2009.05.024

Bazan, N. G., Eady, T. N., Khoutorova, L., Atkins, K. D., Hong, S., Lu, Y., et al. (2012). Novel aspirin-triggered neuroprotectin D1 attenuates cerebral ischemic injury after experimental stroke. Exp. Neurol. 236, 122-130. doi: 10.1016/j. expneurol.2012.04.007

Bazinet, R. P., Metherel, A. H., Chen, C. T., Raza Shaikh, S., Nadjar, A., Joffre, C., et al. (2019). Brain eicosapentaenoic acid metabolism as a lead for novel therapeutics in major depression. Brain Behav. Immun. doi: 10.1016/j. bbi.2019.07.001

Birnie, M., Morrison, R., Camara, R., and Strauss, K. I. (2013). Temporal changes of cytochrome P450 (Cyp) and eicosanoid-related gene expression in the rat brain after traumatic brain injury. BMC Genomics 14, 303. doi: 10.1186/1471-2164-14-303

Bisicchia, E., Sasso, V., Catanzaro, G., Leuti, A., Besharat, Z. M., Chiacchiarini, M., et al. (2018). Resolvin D1 halts remote neuroinflammation and improves functional recovery after focal brain damage via ALX/FPR2 receptor-regulated microRNAs. Mol. Neurobiol. 55, 6894-6905. doi: 10.1007/s12035-018-0889-z

Blais, V., and Rivest, S. (2003). [Role of the innate immune response in the brain]. Med. Sci. (Paris) 19, 981-987. doi: 10.1051/medsci/20031910981

Boudrault, C., Bazinet, R. P., Kang, J. X., and Ma, D. W. (2010). Cyclooxygenase-2 and n-6 PUFA are lower and DHA is higher in the cortex of fat-1 mice. Neurochem. Int. 56, 585-589. doi: 10.1016/j.neuint.2009.12.022

Bourre, J. M., Pascal, G., Durand, G., Masson, M., Dumont, O., and Piciotti, M. (1984). Alterations in the fatty acid composition of rat brain cells (neurons, astrocytes, and oligodendrocytes) and of subcellular fractions (myelin and synaptosomes) induced by a diet devoid of n-3 fatty acids. J. Neurochem. 43, 342-348. doi: 10.1111/j.1471-4159.1984.tb00906.x

Bove, M., Mhillaj, E., Tucci, P., Giardino, I., Schiavone, S., Morgese, M. G., et al. (2018). Effects of n-3 PUFA enriched and n-3 PUFA deficient diets in naïve and A $\beta$-treated female rats. Biochem. Pharmacol. 155, 326-335. doi: 10.1016/j. bcp.2018.07.017

Bowen, R. A., and Clandinin, M. T. (2005). Maternal dietary $22: 6 \mathrm{n}-3$ is more effective than $18: 3 n-3$ in increasing the $22: 6 n-3$ content in phospholipids of glial cells from neonatal rat brain. Br. J. Nutr. 93, 601-611. doi: 10.1079/ BJN20041390

Broadhurst, C. L., Wang, Y., Crawford, M. A., Cunnane, S. C., Parkington, J. E., and Schmidt, W. F. (2002). Brain-specific lipids from marine, lacustrine, or terrestrial food resources: potential impact on early African Homo sapiens. Comp. Biochem. Physiol. B Biochem. Mol. Biol. 131, 653-673. doi: 10.1016/ S1096-4959(02)00002-7

Bystrom, J., Wray, J. A., Sugden, M. C., Holness, M. J., Swales, K. E., Warner, T. D., et al. (2011). Endogenous epoxygenases are modulators of monocyte/ macrophage activity. PLoS One 6, e26591. doi: 10.1371/journal.pone.0026591

Cagnin, A., Brooks, D. J., Kennedy, A. M., Gunn, R. N., Myers, R., Turkheimer, F. E., et al. (2001). In-vivo measurement of activated microglia in dementia. Lancet 358, 461-467. doi: 10.1016/S0140-6736(01)05625-2

Calandria, J. M., and Bazan, N. G. (2010). Neuroprotectin D1 modulates the induction of pro-inflammatory signaling and promotes retinal pigment epithelial cell survival during oxidative stress. Adv. Exp. Med. Biol. 664, 663670. doi: 10.1007/978-1-4419-1399-9_76

Calder, P. C. (2005). Polyunsaturated fatty acids and inflammation. Biochem. Soc. Trans. 33, 423-427. doi: 10.1042/BST0330423

Calder, P. C. (2016). Docosahexaenoic Acid. Ann. Nutr. Metab. 69 Suppl 1, 7-21. doi: $10.1159 / 000448262$

Calder, P. C., Bosco, N., Bourdet-Sicard, R., Capuron, L., Delzenne, N., Doré, J., et al. (2017). Health relevance of the modification of low grade inflammation in ageing (inflammageing) and the role of nutrition. Ageing Res. Rev. 40, 95-119. doi: 10.1016/j.arr.2017.09.001

Carrie, I., Clement, M., de Javel, D., Frances, H., and Bourre, J. M. (2000). Specific phospholipid fatty acid composition of brain regions in mice. Effects of $n-3$ polyunsaturated fatty acid deficiency and phospholipid supplementation. J. Lipid Res. 41, 465-472.

Celis-Morales, C., Livingstone, K. M., Affleck, A., Navas-Carretero, S., SanCristobal, R., Martinez, J. A., et al. (2018). Correlates of overall and central obesity in adults from seven European countries: findings from the Food4Me Study. Eur. J. Clin. Nutr. 72, 207-219. doi: 10.1038/s41430-017-0004-y

Chalon, S. (2006). Omega-3 fatty acids and monoamine neurotransmission. Prostaglandins Leukot. Essent. Fatty Acids 75, 259-269. doi: 10.1016/j. plefa.2006.07.005

Chen, C. T., Liu, Z., and Bazinet, R. P. (2011). Rapid de-esterification and loss of eicosapentaenoic acid from rat brain phospholipids: an intracerebroventricular study. J. Neurochem. 116, 363-373. doi: 10.1111/j.1471-4159.2010.07116.x

Chen, S., Zhang, H., Pu, H., Wang, G., Li, W., Leak, R. K., et al. (2014). n-3 PUFA supplementation benefits microglial responses to myelin pathology. Sci. Rep. 4, 7458. doi: 10.1038/srep07458

Chen, X., Wu, S., Chen, C., Xie, B., Fang, Z., Hu, W., et al. (2017). Omega-3 polyunsaturated fatty acid supplementation attenuates microglial-induced inflammation by inhibiting the HMGB1/TLR4/NF-kappaB pathway following experimental traumatic brain injury. J. Neuroinflamm. 14, 143. doi: 10.1186/ s12974-017-0917-3

Chiang, N., Fredman, G., Backhed, F., Oh, S. F., Vickery, T., Schmidt, B. A., et al. (2012). Infection regulates pro-resolving mediators that lower antibiotic requirements. Nature 484, 524-528. doi: 10.1038/nature11042

Chiang, N., and Serhan, C. N. (2017). Structural elucidation and physiologic functions of specialized pro-resolving mediators and their receptors. Mol. Aspects Med. 58, 114-129. doi: 10.1016/j.mam.2017.03.005

Chinnici, C. M., Yao, Y., and Pratico, D. (2007). The 5-lipoxygenase enzymatic pathway in the mouse brain: young versus old. Neurobiol. Aging 28, 1457-1462. doi: 10.1016/j.neurobiolaging.2006.06.007

Cho, H. P., Nakamura, M. T., and Clarke, S. D. (1999). Cloning, expression, and nutritional regulation of the mammalian Delta-6 desaturase. J. Biol. Chem. 274, 471-477. doi: 10.1074/jbc.274.1.471

Chouinard-Watkins, R., and Bazinet, R. P. (2018). ACSL6 is critical for maintaining brain DHA levels. Proc. Natl. Acad. Sci. U.S.A. 115, 12343-12345. doi: 10.1073/ pnas. 1817557115

Chung, W. L., Chen, J. J., and Su, H. M. (2008). Fish oil supplementation of control and $(n-3)$ fatty acid-deficient male rats enhances reference and working memory performance and increases brain regional docosahexaenoic acid levels. J. Nutr. 138, 1165-1171. doi: 10.1093/jn/138.6.1165

Clària, J., López-Vicario, C., Rius, B., and Titos, E. (2017). Pro-resolving actions of SPM in adipose tissue biology. Mol. Aspects Med. 58, 83-92. doi: 10.1016/j. mam.2017.03.004

Colas, R. A., Shinohara, M., Dalli, J., Chiang, N., and Serhan, C. N. (2014), Identification and signature profiles for pro-resolving and inflammatory lipid mediators in human tissue. Am. J. Physiol. Cell. Physiol. 307, C39-C54. doi: 10.1152/ajpcell.00024.2014

Cooray, S. N., Gobbetti, T., Montero-Melendez, T., McArthur, S., Thompson, D., Clark, A. J., et al. (2013). Ligand-specific conformational change of the G-protein-coupled receptor ALX/FPR2 determines proresolving functional responses. Proc. Natl. Acad. Sci. U. S. A. 110, 18232-18237. doi: 10.1073/pnas.1308253110

Corsi, L., Dongmo, B. M., and Avallone, R. (2015). Supplementation of omega 3 fatty acids improves oxidative stress in activated BV2 microglial cell line. Int. J. Food Sci. Nutr. 66, 293-299. doi: 10.3109/09637486.2014.986073

Crawford, M. A., Bloom, M., Broadhurst, C. L., Schmidt, W. F., Cunnane, S. C., Galli, C., et al. (1999). Evidence for the unique function of docosahexaenoic acid during the evolution of the modern hominid brain. Lipids 34 Suppl, S39S47. doi: $10.1007 / \mathrm{BF} 02562227$

Cunningham, C., and Sanderson, D. J. (2008). Malaise in the water maze: untangling the effects of LPS and IL-1beta on learning and memory. Brain Behav. Immun. 22, 1117-1127. doi: 10.1016/j.bbi.2008.05.007

Czapski, G. A., Gajkowska, B., and Strosznajder, J. B. (2010). Systemic administration of lipopolysaccharide induces molecular and morphological alterations in the hippocampus. Brain Res. 1356, 85-94. doi: 10.1016/j. brainres.2010.07.096 
Dalli, J., and Serhan, C. N. (2012). Specific lipid mediator signatures of human phagocytes: microparticles stimulate macrophage efferocytosis and proresolving mediators. Blood 120, e60-e72. doi: 10.1182/blood-2012-04-423525

Dalli, J., Winkler, J. W., Colas, R. A., Arnardottir, H., Cheng, C. Y., Chiang, N., et al. (2013a). Resolvin D3 and aspirin-triggered resolvin D3 are potent immunoresolvents. Chem. Biol. 20, 188-201. doi: 10.1016/j. chembiol.2012.11.010

Dalli, J., Zhu, M., Vlasenko, N. A., Deng, B., Haeggstrom, J. Z., Petasis, N. A., et al. (2013b). The novel 13S,14S-epoxy-maresin is converted by human macrophages to maresin 1 (MaR1), inhibits leukotriene A4 hydrolase (LTA4H), and shifts macrophage phenotype. FASEB J. 27, 2573-2583. doi: 10.1096/ff.13-227728

Davidson, J., Abul, H. T., Milton, A. S., and Rotondo, D. (2001). Cytokines and cytokine inducers stimulate prostaglandin E2 entry into the brain. Pflugers Arch. 442, 526-533. doi: 10.1007/s004240100572

De Smedt-Peyrusse, V., Sargueil, F., Moranis, A., Harizi, H., Mongrand, S., and Layé, S. (2008). Docosahexaenoic acid prevents lipopolysaccharide-induced cytokine production in microglial cells by inhibiting lipopolysaccharide receptor presentation but not its membrane subdomain localization. J. Neurochem. 105, 296-307. doi: 10.1111/j.1471-4159.2007.05129.x

de Theije, C. G., van den Elsen, L. W., Willemsen, L. E., Milosevic, V., Korte-Bouws, G. A., Lopes da Silva, S., et al. (2015). Dietary long chain n-3 polyunsaturated fatty acids prevent impaired social behaviour and normalize brain dopamine levels in food allergic mice. Neuropharmacology 90, 15-22. doi: 10.1016/j.neuropharm.2014.11.001

Dehkordi, N. G., Noorbakhshnia, M., Ghaedi, K., Esmaeili, A., and Dabaghi, M. (2015). Omega-3 fatty acids prevent LPS-induced passive avoidance learning and memory and CaMKII-alpha gene expression impairments in hippocampus of rat. Pharmacol. Rep. 67, 370-375. doi: 10.1016/j.pharep.2014.10.014

Delpech, J.-C., Madore, C., Joffre, C., Aubert, A., Kang, J. X., Nadjar, A., et al. (2015a). Transgenic increase in $n-3 / n-6$ fatty acid ratio protects against cognitive deficits induced by an immune challenge through decrease of neuroinflammation. Neuropsychopharmacology 40, 525-536. doi: 10.1038/npp.2014.196

Delpech, J.-C., Thomazeau, A., Madore, C., Bosch-Bouju, C., Larrieu, T., Lacabanne, C., et al. (2015b). Dietary n-3 PUFAs deficiency increases vulnerability to inflammation-induced spatial memory impairment. Neuropsychopharmacology 40, 2774-2787. doi: 10.1038/npp.2015.127

Destaillats, F., Joffre, C., Acar, N., Joffre, F., Bezelgues, J. B., Pasquis, B., et al. (2010). Differential effect of maternal diet supplementation with alphaLinolenic adcid or n-3 long-chain polyunsaturated fatty acids on glial cell phosphatidylethanolamine and phosphatidylserine fatty acid profile in neonate rat brains. Nutr. Metab. (Lond.) 7, 2. doi: 10.1186/1743-7075-7-2

Deyama, S., Ishikawa, Y., Yoshikawa, K., Shimoda, K., Ide, S., Satoh, M., et al. (2017). Resolvin D1 and D2 reverse lipopolysaccharide-induced depression-like behaviors through the mTORC1 signaling pathway. Int. J. Neuropsychopharmacol. 20, 575-584. doi: 10.1093/ijnp/pyx023

Deyama, S., Shimoda, K., Ikeda, H., Fukuda, H., Shuto, S., and Minami, M. (2018a). Resolvin E3 attenuates lipopolysaccharide-induced depression-like behavior in mice. J. Pharmacol. Sci. 138, 86-88. doi: 10.1016/j.jphs.2018.09.006

Deyama, S., Shimoda, K., Suzuki, H., Ishikawa, Y., Ishimura, K., Fukuda, H., et al. (2018b). Resolvin E1/E2 ameliorate lipopolysaccharide-induced depression-like behaviors via ChemR23. Psychopharmacol. (Berl.) 235, 329-336. doi: 10.1007/ s00213-017-4774-7

Di Meco, A., Lauretti, E., Vagnozzi, A. N., and Pratico, D. (2014). Zileuton restores memory impairments and reverses amyloid and tau pathology in aged Alzheimer's disease mice. Neurobiol. Aging 35, 2458-2464. doi: 10.1016/j. neurobiolaging.2014.05.016

Dieter, P., Scheibe, R., Kamionka, S., and Kolada, A. (2002). LPS-induced synthesis and release of PGE2 in liver macrophages: regulation by CPLA2, COX-1, COX-2, and PGE2 synthase. Adv. Exp. Med. Biol. 507, 457-462. doi: 10.1007/978-1-4615-0193-0_71

Dong, Y., Xu, M., Kalueff, A. V., and Song, C. (2017). Dietary eicosapentaenoic acid normalizes hippocampal omega- 3 and 6 polyunsaturated fatty acid profile, attenuates glial activation and regulates BDNF function in a rodent model of neuroinflammation induced by central interleukin-1beta administration. Eur. J. Nutr. doi: 10.1007/s00394-017-1462-7

Doyle, R., Sadlier, D. M., and Godson, C. (2018). Pro-resolving lipid mediators: agents of anti-ageing? Semin. Immunol. 40, 36-48. doi: 10.1016/j. smim.2018.09.002
Dyerberg, J., and Bang, H. O. (1979). Haemostatic function and platelet polyunsaturated fatty acids in Eskimos. Lancet 2, 433-435. doi: 10.1016/ S0140-6736(79)91490-9

Engstrom, L., Ruud, J., Eskilsson, A., Larsson, A., Mackerlova, L., Kugelberg, U., et al. (2012). Lipopolysaccharide-induced fever depends on prostaglandin E2 production specifically in brain endothelial cells. Endocrinology 153, 48494861. doi: 10.1210/en.2012-1375

Famenini, S., Rigali, E. A., Olivera-Perez, H. M., Dang, J., Chang, M. T., Halder, R., et al. (2017). Increased intermediate M1-M2 macrophage polarization and improved cognition in mild cognitive impairment patients on omega-3 supplementation. FASEB J. 31, 148-160. doi: 10.1096/fj.201600677RR

Farias, S. E., Basselin, M., Chang, L., Heidenreich, K. A., Rapoport, S. I., and Murphy, R. C. (2008). Formation of eicosanoids, E2/D2 isoprostanes, and docosanoids following decapitation-induced ischemia, measured in highenergy-microwaved rat brain. J. Lipid Res. 49, 1990-2000. doi: 10.1194/jlr. M800200-JLR200

Farooqui, A. A., and Horrocks, L. A. (2006). Phospholipase A2-generated lipid mediators in the brain: the good, the bad, and the ugly. Neuroscientist 12, 245260. doi: $10.1177 / 1073858405285923$

Fernandez, R. F., Kim, S. Q., Zhao, Y., Foguth, R. M., Weera, M. M., Counihan, J. L., et al. (2018). Acyl-CoA synthetase 6 enriches the neuroprotective omega-3 fatty acid DHA in the brain. Proc. Natl. Acad. Sci. U. S. A. 115, 12525-12530. doi: 10.1073/pnas.1807958115

Fleming, I. (2011). Cytochrome P450-dependent eicosanoid production and crosstalk. Curr. Opin. Lipidol. 22, 403-409. doi: 10.1097/MOL.0b013e32834a9790

Fourrier, C., Remus-Borel, J., Greenhalgh, A. D., Guichardant, M., BernoudHubac, N., Lagarde, M., et al. (2017). Docosahexaenoic acid-containing choline phospholipid modulates LPS-induced neuroinflammation in vivo and in microglia in vitro. J. Neuroinflamm. 14, 170. doi: 10.1186/s12974-017-0939-x

Francos-Quijorna, I., Santos-Nogueira, E., Gronert, K., Sullivan, A. B., Kopp, M. A., Brommer, B., et al. (2017). Maresin 1 promotes inflammatory resolution, neuroprotection, and functional neurological recovery after spinal cord injury. J. Neurosci. 37, 11731-11743. doi: 10.1523/JNEUROSCI.1395-17.2017

Fredman, G., Sadhu, S., and Rymut, N. (2017). Fine-tuning inflammationresolution programs: focus on atherosclerosis. Curr. Opin. Clin. Nutr. Metab. Care 20, 117-123. doi: 10.1097/MCO.0000000000000351

Fredman, G., and Serhan, C. N. (2011). Specialized proresolving mediator targets for RvE1 and RvD1 in peripheral blood and mechanisms of resolution. Biochem. J. 437, 185-197. doi: 10.1042/BJ20110327

Freund-Levi, Y., Eriksdotter-Jonhagen, M., Cederholm, T., Basun, H., Faxen-Irving, G., Garlind, A., et al. (2006). Omega-3 fatty acid treatment in 174 patients with mild to moderate Alzheimer disease: OmegAD study: a randomized double-blind trial. Arch. Neurol. 63, 1402-1408. doi: 10.1001/archneur.63.10.1402

Furuyashiki, T., Akiyama, S., and Kitaoka, S. (2019). Roles of multiple lipid mediators in stress and depression. Int. Immunol. 1781-1791. doi: 10.1093/ intimm/dxz023

Gabbs, M., Leng, S., Devassy, J. G., Moniruijaman, M., and Aukema, H. M. (2015). Advances in our understanding of oxylipins derived from dietary PUFAs. Adv. Nutr. 6, 513-540. doi: 10.3945/an.114.007732

Gilbert, K., Bernier, J., Godbout, R., and Rousseau, G. (2014). Resolvin D1, a metabolite of omega-3 polyunsaturated fatty acid, decreases post-myocardial infarct depression. Mar. Drugs 12, 5396-5407. doi: 10.3390/md12115396

Gilroy, D. W., Edin, M. L., De Maeyer, R. P., Bystrom, J., Newson, J., Lih, F. B., et al. (2016). CYP450-derived oxylipins mediate inflammatory resolution. Proc. Natl. Acad. Sci. U. S. A. 113, E3240-E3249. doi: 10.1073/ pnas. 1521453113

Graham, K. L., Zabel, B. A., Loghavi, S., Zuniga, L. A., Ho, P. P., Sobel, R. A., et al. (2009). Chemokine-like receptor-1 expression by central nervous system-infiltrating leukocytes and involvement in a model of autoimmune demyelinating disease. J. Immunol. 183, 6717-6723. doi: 10.4049/ jimmunol.0803435

Griffin, W. S., Stanley, L. C., Ling, C., White, L., MacLeod, V., Perrot, L. J., et al. (1989). Brain interleukin 1 and S-100 immunoreactivity are elevated in Down syndrome and Alzheimer disease. Proc. Natl. Acad. Sci. U. S. A. 86, 7611-7615. doi: $10.1073 /$ pnas.86.19.7611

Guo, X., Fu, Y., Xu, Y., Weng, S., Liu, D., Cui, D., et al. (2012). Chronic mild restraint stress rats decreased CMKLR1 expression in distinct brain region. Neurosci. Lett. 524, 25-29. doi: 10.1016/j.neulet.2012.06.075 
Guo, Z., Hu, Q., Xu, L., Guo, Z. N., Ou, Y., He, Y., et al. (2016). Lipoxin A4 reduces inflammation through formyl peptide receptor 2/p38 MAPK signaling pathway in subarachnoid hemorrhage rats. Stroke 47, 490-497. doi: 10.1161/ STROKEAHA.115.011223

Halade, G. V., Black, L. M., and Verma, M. K. (2018). Paradigm shift - metabolic transformation of docosahexaenoic and eicosapentaenoic acids to bioactives exemplify the promise of fatty acid drug discovery. Biotechnol. Adv. 36, 935- 953. doi: 10.1016/j.biotechadv.2018.02.014

Hanisch, U. K., and Kettenmann, H. (2007). Microglia: active sensor and versatile effector cells in the normal and pathologic brain. Nat. Neurosci. 10, 1387-1394. doi: $10.1038 / \mathrm{nn} 1997$

Harrison, J. L., Rowe, R. K., Ellis, T. W., Yee, N. S., O’Hara, B. F., Adelson, P. D., et al. (2015). Resolvins AT-D1 and E1 differentially impact functional outcome, post-traumatic sleep, and microglial activation following diffuse brain injury in the mouse. Brain Behav. Immun. 47, 131-140. doi: 10.1016/j.bbi.2015.01.001

Hashimoto, M., Katakura, M., Tanabe, Y., Al Mamun, A., Inoue, T., Hossain, S., et al. (2015). n-3 fatty acids effectively improve the reference memory-related learning ability associated with increased brain docosahexaenoic acid-derived docosanoids in aged rats. Biochim. Biophys. Acta 1851, 203-209. doi: 10.1016/j. bbalip.2014.10.009

Hecker, M., Sommer, N., Foch, S., Hecker, A., Hackstein, H., Witzenrath, M., et al. (2018). Resolvin E1 and its precursor 18R-HEPE restore mitochondrial function in inflammation. Biochim. Biophys. Acta Mol. Cell. Biol. Lipids 1863, 1016-1028. doi: 10.1016/j.bbalip.2018.06.011

Hennebelle, M., Zhang, Z., Metherel, A. H., Kitson, A. P., Otoki, Y., Richardson, C. E., et al. (2017). Linoleic acid participates in the response to ischemic brain injury through oxidized metabolites that regulate neurotransmission. Sci. Rep. 7, 4342. doi: 10.1038/s41598-017-02914-7

Hiratsuka, S., Koizumi, K., Ooba, T., and Yokogoshi, H. (2009). Effects of dietary docosahexaenoic acid connecting phospholipids on the learning ability and fatty acid composition of the brain. J. Nutr. Sci. Vitaminol. (Tokyo) 55, 374-380. doi: $10.3177 /$ jnsv. 55.374

Hjorth, E., Zhu, M., Toro, V. C., Vedin, I., Palmblad, J., Cederholm, T., et al. (2013). Omega-3 fatty acids enhance phagocytosis of Alzheimer's disease-related amyloid-beta 42 by human microglia and decrease inflammatory markers. J. Alzheimers Dis. 35, 697-713. doi: 10.3233/JAD-130131

Hong, S., Gronert, K., Devchand, P. R., Moussignac, R. L., and Serhan, C. N. (2003). Novel docosatrienes and 17S-resolvins generated from docosahexaenoic acid in murine brain, human blood, and glial cells. Autacoids in anti-inflammation. J. Biol. Chem. 278, 14677-14687. doi: 10.1074/jbc.M300218200

Hughes, M. M., Connor, T. J., and Harkin, A. (2016). Stress-related immune markers in depression: implications for treatment. Int. J. Neuropsychopharmacol. 1-19. doi: 10.1093/ijnp/pyw001

Igarashi, M., Ma, K., Chang, L., Bell, J. M., and Rapoport, S. I. (2007). Dietary n-3 PUFA deprivation for 15 weeks upregulates elongase and desaturase expression in rat liver but not brain. J. Lipid Res. 48, 2463-2470. doi: 10.1194/ jlr.M700315-JLR200

Inoue, T., Tanaka, M., Masuda, S., Ohue-Kitano, R., Yamakage, H., Muranaka, K., et al. (2017). Omega-3 polyunsaturated fatty acids suppress the inflammatory responses of lipopolysaccharide-stimulated mouse microglia by activating SIRT1 pathways. Biochim. Biophys. Acta 1862, 552-560. doi: 10.1016/j. bbalip.2017.02.010

Ishikawa, Y., Deyama, S., Shimoda, K., Yoshikawa, K., Ide, S., Satoh, M., et al. (2017). Rapid and sustained antidepressant effects of resolvin D1 and D2 in a chronic unpredictable stress model. Behav. Brain Res. 332, 233-236. doi: 10.1016/j.bbr.2017.06.010

Isobe, Y., Arita, M., Matsueda, S., Iwamoto, R., Fujihara, T., Nakanishi, H., et al. (2012). Identification and structure determination of novel anti-inflammatory mediator resolvin E3, 17,18-dihydroxyeicosapentaenoic acid. J. Biol. Chem. 287, 10525-10534. doi: 10.1074/jbc.M112.340612

James, S. Y., Williams, M. A., Kelsey, S. M., Newland, A. C., and Colston, K. W. (1997). The role of vitamin D derivatives and retinoids in the differentiation of human leukaemia cells. Biochem. Pharmacol. 54, 625-634. doi: 10.1016/ S0006-2952(97)00195-0

Joffre, C., Grégoire, S., De Smedt, V., Acar, N., Bretillon, L., Nadjar, A., et al. (2016). Modulation of brain PUFA content in different experimental models of mice. Prostaglandins Leukot. Essent. Fatty Acids 114, 1-10. doi: 10.1016/j. plefa.2016.09.003
Kang, J. X., Wang, J., Wu, L., and Kang, Z. B. (2004). Transgenic mice: fat-1 mice convert n-6 to n-3 fatty acids. Nature 427, 504. doi: 10.1038/427504a

Kantarci, A., Aytan, N., Palaska, I., Stephens, D., Crabtree, L., Benincasa, C., et al. (2018). Combined administration of resolvin E1 and lipoxin A4 resolves inflammation in a murine model of Alzheimer's disease. Exp. Neurol. 300, 111120. doi: 10.1016/j.expneurol.2017.11.005

Kavanagh, T., Lonergan, P. E., and Lynch, M. A. (2004). Eicosapentaenoic acid and gamma-linolenic acid increase hippocampal concentrations of IL-4 and IL-10 and abrogate lipopolysaccharide-induced inhibition of long-term potentiation. Prostaglandins Leukot. Essent. Fatty Acids 70, 391-397. doi: 10.1016/j. plefa.2003.12.014

Kiecolt-Glaser, J. K., Belury, M. A., Andridge, R., Malarkey, W. B., Hwang, B. S., and Glaser, R. (2012). Omega-3 supplementation lowers inflammation in healthy middle-aged and older adults: a randomized controlled trial. Brain Behav. Immun. 26, 988-995. doi: 10.1016/j.bbi.2012.05.011

Kim, H. W., Rao, J. S., Rapoport, S. I., and Igarashi, M. (2011). Dietary n-6 PUFA deprivation downregulates arachidonate but upregulates docosahexaenoate metabolizing enzymes in rat brain. Biochim. Biophys. Acta 1811, 111-117. doi: 10.1016/j.bbalip.2010.10.005

Kitson, A. P., Metherel, A. H., Chen, C. T., Domenichiello, A. F., Trepanier, M. O., Berger, A., et al. (2016). Effect of dietary docosahexaenoic acid (DHA) in phospholipids or triglycerides on brain DHA uptake and accretion. J. Nutr. Biochem. 33, 91-102. doi: 10.1016/j.jnutbio.2016.02.009

Klein, C. P., Sperotto, N. D., Maciel, I. S., Leite, C. E., Souza, A. H., and Campos, M. M. (2014). Effects of D-series resolvins on behavioral and neurochemical changes in a fibromyalgia-like model in mice. Neuropharmacology 86, 57-66. doi: 10.1016/j.neuropharm.2014.05.043

Kremer, J. M. (2000). n-3 fatty acid supplements in rheumatoid arthritis. Am. J. Clin. Nutr. 71, 349S-351S. doi: 10.1093/ajen/71.1.349s

Kremer, J. M., Lawrence, D. A., Jubiz, W., DiGiacomo, R., Rynes, R., Bartholomew, L. E., et al. (1990). Dietary fish oil and olive oil supplementation in patients with rheumatoid arthritis. Clinical and immunologic effects. Arthritis Rheum. 33, 810-820. doi: 10.1002/art.1780330607

Krishnamoorthy, S., Recchiuti, A., Chiang, N., Fredman, G., and Serhan, C. N. (2012). Resolvin D1 receptor stereoselectivity and regulation of inflammation and proresolving microRNAs. Am. J. Pathol. 180, 2018-2027. doi: 10.1016/j. ajpath.2012.01.028

Krishnamoorthy, S., Recchiuti, A., Chiang, N., Yacoubian, S., Lee, C. H., Yang, R., et al. (2010). Resolvin D1 binds human phagocytes with evidence for proresolving receptors. Proc. Natl. Acad. Sci. U. S. A. 107, 1660-1665. doi: 10.1073/pnas.0907342107

Kromann, N., and Green, A. (1980). Epidemiological studies in the Upernavik district, Greenland. Incidence of some chronic diseases 1950-1974. Acta Med. Scand. 208, 401-406. doi: 10.1111/j.0954-6820.1980.tb01221.x

Kuda, O. (2017). Bioactive metabolites of docosahexaenoic acid. Biochimie 136, 12-20. doi: 10.1016/j.biochi.2017.01.002

Labrousse, V. F., Nadjar, A., Joffre, C., Costes, L., Aubert, A., Grégoire, S., et al. (2012). Short-term long chain omega3 diet protects from neuroinflammatory processes and memory impairment in aged mice. PLoS One 7, e36861. doi: 10.1371/journal.pone.0036861

Lacombe, R. J. S., Giuliano, V., Colombo, S. M., Arts, M. T., and Bazinet, R. P. (2017). Compound-specific isotope analysis resolves the dietary origin of docosahexaenoic acid in the mouse brain. J. Lipid Res. 58, 2071-2081. doi: 10.1194/jlr.D077990

Lafourcade, M., Larrieu, T., Mato, S., Duffaud, A., Sepers, M., Matias, I., et al. (2011). Nutritional omega-3 deficiency abolishes endocannabinoid-mediated neuronal functions. Nat. Neurosci. 14, 345-350. doi: 10.1038/nn.2736

Larrieu, T., Hilal, M. L., Hilal, L. M., Fourrier, C., De Smedt-Peyrusse, V., Sans, N., et al. (2014). Nutritional omega-3 modulates neuronal morphology in the prefrontal cortex along with depression-related behaviour through corticosterone secretion. Transl. Psychiatry 4, e437. doi: 10.1038/tp.2014.77

Larrieu, T., and Layé, S. (2018). Food for mood: relevance of nutritional omega-3 fatty acids for depression and anxiety. Front. Physiol. 9, 1047. doi: 10.3389/ fphys.2018.01047

Larrieu, T., Madore, C., Joffre, C., and Layé, S. (2012). Nutritional n-3 polyunsaturated fatty acids deficiency alters cannabinoid receptor signaling pathway in the brain and associated anxiety-like behavior in mice. J. Physiol. Biochem. 68, 671-681. doi: 10.1007/s13105-012-0179-6 
Layé, S. (2010). Polyunsaturated fatty acids, neuroinflammation and well being Prostaglandins Leukot. Essent. Fatty Acids 82, 295-303. doi: 10.1016/j. plefa.2010.02.006

Layé, S., Nadjar, A., Joffre, C., and Bazinet, R. P. (2018). Anti-inflammatory effects of omega-3 fatty acids in the brain: physiological mechanisms and relevance to pharmacology. Pharmacol. Rev. 70, 12-38. doi: 10.1124/pr.117.014092

Lazic, M., Inzaugarat, M. E., Povero, D., Zhao, I. C., Chen, M., Nalbandian, M., et al. (2014). Reduced dietary omega- 6 to omega-3 fatty acid ratio and 12/15-lipoxygenase deficiency are protective against chronic high fat diet-induced steatohepatitis. PLoS One 9, e107658. doi: 10.1371/journal. pone. 0107658

Lee, L. K., Shahar, S., Chin, A. V., and Yusoff, N. A. (2013). Docosahexaenoic acid-concentrated fish oil supplementation in subjects with mild cognitive impairment (MCI): a 12-month randomised, double-blind, placebo-controlled trial. Psychopharmacol. (Berl.) 225, 605-612. doi: 10.1007/s00213-012-2848-0

Levy, B. D., Clish, C. B., Schmidt, B., Gronert, K., and Serhan, C. N. (2001). Lipid mediator class switching during acute inflammation: signals in resolution. Nat. Immunol. 2, 612-619. doi: 10.1038/89759

Li, L., Wu, Y., Wang, Y., Wu, J., Song, L., Xian, W., et al. (2014). Resolvin D1 promotes the interleukin-4-induced alternative activation in BV-2 microglial cells. J. Neuroinflamm. 11, 72. doi: 10.1186/1742-2094-11-72

Little, S. J., Lynch, M. A., Manku, M., and Nicolaou, A. (2007). Docosahexaenoic acid-induced changes in phospholipids in cortex of young and aged rats: a lipidomic analysis. Prostaglandins Leukot. Essent. Fatty Acids 77, 155-162. doi: 10.1016/j.plefa.2007.08.009

Lonergan, P. E., Martin, D. S., Horrobin, D. F., and Lynch, M. A. (2004). Neuroprotective actions of eicosapentaenoic acid on lipopolysaccharideinduced dysfunction in rat hippocampus. J. Neurochem. 91, 20-29. doi: 10.1111/j.1471-4159.2004.02689.x

López-Vicario, C., Rius, B., Alcaraz-Quiles, J., García-Alonso, V., Lopategi, A., Titos, E., et al. (2016). Pro-resolving mediators produced from EPA and DHA: Overview of the pathways involved and their mechanisms in metabolic syndrome and related liver diseases. Eur. J. Pharmacol. 785, 133-143. doi: 10.1016/j.ejphar.2015.03.092

Lu, D. Y., Tsao, Y. Y., Leung, Y. M., and Su, K. P. (2010). Docosahexaenoic acid suppresses neuroinflammatory responses and induces heme oxygenase- 1 expression in BV-2 microglia: implications of antidepressant effects for omega-3 fatty acids. Neuropsychopharmacology 35, 2238-2248. doi: 10.1038/npp.2010.98

Lu, Y., Zhao, L. X., Cao, D. L., and Gao, Y. J. (2013). Spinal injection of docosahexaenoic acid attenuates carrageenan-induced inflammatory pain through inhibition of microglia-mediated neuroinflammation in the spinal cord. Neuroscience 241, 22-31. doi: 10.1016/j.neuroscience.2013.03.003

Lukiw, W. J., Cui, J. G., Marcheselli, V. L., Bodker, M., Botkjaer, A., Gotlinger, K., et al. (2005). A role for docosahexaenoic acid-derived neuroprotectin D1 in neural cell survival and Alzheimer disease. J. Clin. Invest. 115, 2774-2783. doi: $10.1172 /$ JCI25420

Luo, C., Ren, H., Wan, J. B., Yao, X., Zhang, X., He, C., et al. (2014). Enriched endogenous omega- 3 fatty acids in mice protect against global ischemia injury. J. Lipid Res. 55, 1288-1297. doi: 10.1194/jlr.M046466

Madore, C., Leyrolle, Q., Lacabanne, C., Benmamar-Badel, A., Joffre, C., Nadjar, A., et al. (2016). Neuroinflammation in autism: plausible role of maternal inflammation, dietary omega 3 , and microbiota. Neural. Plast. 2016, 3597209. doi: 10.1155/2016/3597209

Madore, C., Nadjar, A., Delpech, J.-C., Sere, A., Aubert, A., Portal, C., et al. (2014). Nutritional n-3 PUFAs deficiency during perinatal periods alters brain innate immune system and neuronal plasticity-associated genes. Brain Behav. Immun. 41, 22-31. doi: 10.1016/j.bbi.2014.03.021

Manduca, A., Bara, A., Larrieu, T., Lassalle, O., Joffre, C., Layé, S., et al. (2017). Amplification of mGlu5-endocannabinoid signaling rescues behavioral and synaptic deficits in a mouse model of adolescent and adult dietary polyunsaturated fatty acid imbalance. J. Neurosci. 37, 6851-6868. doi: 10.1523/ JNEUROSCI.3516-16.2017

Marcheselli, V. L., Hong, S., Lukiw, W. J., Tian, X. H., Gronert, K., Musto, A., et al. (2003). Novel docosanoids inhibit brain ischemia-reperfusion-mediated leukocyte infiltration and pro-inflammatory gene expression. J. Biol. Chem. 278, 43807-43817. doi: 10.1074/jbc.M305841200

Marcon, R., Bento, A. F., Dutra, R. C., Bicca, M. A., Leite, D. F., and Calixto, J. B. (2013). Maresin 1, a proresolving lipid mediator derived from omega-3 polyunsaturated fatty acids, exerts protective actions in murine models of colitis. J. Immunol. 191, 4288-4298. doi: 10.4049/jimmunol.1202743

Mas, E., Croft, K. D., Zahra, P., Barden, A., and Mori, T. A. (2012). Resolvins D1, D2, and other mediators of self-limited resolution of inflammation in human blood following n-3 fatty acid supplementation. Clin. Chem. 58, 1476-1484. doi: 10.1373/clinchem.2012.190199

McNamara, R. K. (2015). Mitigation of inflammation-induced mood dysregulation by long-chain omega-3 fatty acids. J. Am. Coll. Nutr. 34 Suppl 1, 48-55. doi: 10.1080/07315724.2015.1080527

McNamara, R. K., and Carlson, S. E. (2006). Role of omega-3 fatty acids in brain development and function: potential implications for the pathogenesis and prevention of psychopathology. Prostaglandins Leukot. Essent. Fatty Acids 75, 329-349. doi: 10.1016/j.plefa.2006.07.010

Mingam, R., Moranis, A., Bluthé, R.-M., De Smedt-Peyrusse, V., Kelley, K. W., Guesnet, P., et al. (2008). Uncoupling of interleukin-6 from its signalling pathway by dietary $\mathrm{n}$-3-polyunsaturated fatty acid deprivation alters sickness behaviour in mice. Eur. J. Neurosci. 28, 1877-1886. doi: 10.1111/j.1460-9568.2008.06470.x

Mizwicki, M. T., Liu, G., Fiala, M., Magpantay, L., Sayre, J., Siani, A., et al. (2013). 1alpha,25-dihydroxyvitamin D3 and resolvin D1 retune the balance between amyloid-beta phagocytosis and inflammation in Alzheimer's disease patients. J. Alzheimers Dis. 34, 155-170. doi: 10.3233/JAD-121735

Moon, D. O., Kim, K. C., Jin, C. Y., Han, M. H., Park, C., Lee, K. J., et al. (2007). Inhibitory effects of eicosapentaenoic acid on lipopolysaccharide-induced activation in BV2 microglia. Int. Immunopharmacol. 7, 222-229. doi: 10.1016/j.intimp.2006.10.001

Morgese, M. G., Schiavone, S., Mhillaj, E., Bove, M., Tucci, P., and Trabace, L. (2018). N-3 PUFA diet enrichment prevents amyloid beta-induced depressivelike phenotype. Pharmacol. Res. 129, 526-534. doi: 10.1016/j.phrs.2017.11.034

Mulik, R. S., Bing, C., Ladouceur-Wodzak, M., Munaweera, I., Chopra, R., and Corbin, I. R. (2016). Localized delivery of low-density lipoprotein docosahexaenoic acid nanoparticles to the rat brain using focused ultrasound. Biomaterials 83, 257-268. doi: 10.1016/j.biomaterials.2016.01.021

Nadjar, A., Tridon, V., May, M. J., Ghosh, S., Dantzer, R., Amedee, T., et al. (2005). NFkappaB activates in vivo the synthesis of inducible Cox-2 in the brain. $J$ Cereb. Blood Flow Metab. 25, 1047-1059. doi: 10.1038/s.j.jbfm.9600106

Nassar, G. M., Morrow, J. D., Roberts, L. J., Lakkis, F. G., and Badr, K. F. (1994). Induction of 15-lipoxygenase by interleukin-13 in human blood monocytes. J. Biol. Chem. 269, 27631-27634

Nebert, D. W. (2017). Aryl hydrocarbon receptor (AHR): "pioneer member" of the basic-helix/loop/helix per-Arnt-sim (bHLH/PAS) family of "sensors" of foreign and endogenous signals. Prog. Lipid Res. 67, 38-57. doi: 10.1016/j. plipres.2017.06.001

Nebert, D. W., Wikvall, K., and Miller, W. L. (2013). Human cytochromes P450 in health and disease. Philos. Trans. R. Soc. Lond. B Biol. Sci. 368, 20120431. doi: 10.1098/rstb.2012.0431

Norling, L. V., Headland, S. E., Dalli, J., Arnardottir, H. H., Haworth, O., Jones, H. R., et al. (2016). Proresolving and cartilage-protective actions of resolvin D1 in inflammatory arthritis. JCI Insight 1, e85922. doi: 10.1172/jci. insight. 85922

Oh, S. F., Pillai, P. S., Recchiuti, A., Yang, R., and Serhan, C. N. (2011). Pro-resolving actions and stereoselective biosynthesis of $18 \mathrm{~S}$ E-series resolvins in human leukocytes and murine inflammation. J. Clin. Invest. 121, 569-581. doi: 10.1172/ JCI42545

Ohira, T., Arita, M., Omori, K., Recchiuti, A., Van Dyke, T. E., and Serhan, C. N. (2010). Resolvin E1 receptor activation signals phosphorylation and phagocytosis. J. Biol. Chem. 285, 3451-3461. doi: 10.1074/jbc.M109.044131

Orr, S. K., Palumbo, S., Bosetti, F., Mount, H. T., Kang, J. X., Greenwood, C. E., et al. (2013). Unesterified docosahexaenoic acid is protective in neuroinflammation. J. Neurochem. 378-393. doi: 10.1111/jnc. 12392

Ostermann, A. I., Reutzel, M., Hartung, N., Franke, N., Kutzner, L., Schoenfeld, K., et al. (2017). A diet rich in omega-3 fatty acids enhances expression of soluble epoxide hydrolase in murine brain. Prostaglandins Other Lipid Mediat. 79-87. doi: 10.1016/j.prostaglandins.2017.06.001

Pallast, S., Arai, K., Wang, X., Lo, E. H., and van Leyen, K. (2009). 12/15-Lipoxygenase targets neuronal mitochondria under oxidative stress. J. Neurochem. 111, 882-889. doi: 10.1111/j.1471-4159.2009.06379.x

Park, C.-K., Xu, Z.-Z., Liu, T., Lü, N., Serhan, C. N., and Ji, R.-R. (2011). Resolvin D2 is a potent endogenous inhibitor for transient receptor potential subtype 
V1/A1, inflammatory pain, and spinal cord synaptic plasticity in mice: distinct roles of resolvin D1, D2, and E1. J. Neurosci. 31, 18433-18438. doi: 10.1523/ JNEUROSCI.4192-11.2011

Pascual, O., Ben Achour, S., Rostaing, P., Triller, A., and Bessis, A. (2012). Microglia activation triggers astrocyte-mediated modulation of excitatory neurotransmission. Proc. Natl. Acad. Sci. U. S. A. 109, E197-E205. doi: 10.1073/pnas.1111098109

Perretti, M., Chiang, N., La, M., Fierro, I. M., Marullo, S., Getting, S. J., et al. (2002). Endogenous lipid- and peptide-derived anti-inflammatory pathways generated with glucocorticoid and aspirin treatment activate the lipoxin A4 receptor. Nat. Med. 8, 1296-1302. doi: 10.1038/nm786

Pettit, L. K., Varsanyi, C., Tadros, J., and Vassiliou, E. (2013). Modulating the inflammatory properties of activated microglia with Docosahexaenoic acid and Aspirin. Lipids Health Dis. 12, 16. doi: 10.1186/1476-511X-12-16

Pietropaolo, S., Goubran, M. G., Joffre, C., Aubert, A., Lemaire-Mayo, V., Crusio, W. E., et al. (2014). Dietary supplementation of omega-3 fatty acids rescues fragile X phenotypes in Fmr1-Ko mice. Psychoneuroendocrinology 49, 119-129. doi: 10.1016/j.psyneuen.2014.07.002

Pratico, D., Zhukareva, V., Yao, Y., Uryu, K., Funk, C. D., Lawson, J. A., et al. (2004). 12/15-lipoxygenase is increased in Alzheimer's disease: possible involvement in brain oxidative stress. Am. J. Pathol. 164, 1655-1662. doi: $10.1016 /$ S0002-9440(10)63724-8

Qu, L., and Caterina, M. J. (2018). Accelerating the reversal of inflammatory pain with NPD1 and its receptor GPR37. J. Clin. Invest. 128, 3246-3249. doi: 10.1172/JCI122203

Rao, J. S., Ertley, R. N., DeMar, J. C., Jr., Rapoport, S. I., Bazinet, R. P., and Lee, H. J. (2007). Dietary n-3 PUFA deprivation alters expression of enzymes of the arachidonic and docosahexaenoic acid cascades in rat frontal cortex. Mol. Psychiatry 12, 151-157. doi: 10.1038/sj.mp.4001887

Rapaport, M. H., Nierenberg, A. A., Schettler, P. J., Kinkead, B., Cardoos, A., Walker, R., et al. (2016). Inflammation as a predictive biomarker for response to omega-3 fatty acids in major depressive disorder: a proof-of-concept study. Mol. Psychiatry 21, 71-79. doi: 10.1038/mp.2015.22

Rapoport, S. I., Rao, J. S., and Igarashi, M. (2007). Brain metabolism of nutritionally essential polyunsaturated fatty acids depends on both the diet and the liver. Prostaglandins Leukot. Essent. Fatty Acids 77, 251-261. doi: 10.1016/j. plefa.2007.10.023

Recchiuti, A. (2013). Resolvin D1 and its GPCRs in resolution circuits of inflammation. Prostaglandins Other Lipid Mediat. 107, 64-76. doi: 10.1016/j. prostaglandins.2013.02.004

Recchiuti, A., Krishnamoorthy, S., Fredman, G., Chiang, N., and Serhan, C. N. (2011). MicroRNAs in resolution of acute inflammation: identification of novel resolvin D1-miRNA circuits. Faseb J. 25, 544-560. doi: 10.1096/ff.10-169599

Renaud, J., Therien, H. M., Plouffe, M., and Martinoli, M. G. (2015). [Neuroinflammation: Dr Jekyll or Mr Hyde?]. Med. Sci. (Paris) 31, 979-988. doi: $10.1051 /$ medsci $/ 20153111012$

Rey, C., Delpech, J. C., Madore, C., Nadjar, A., Greenhalgh, A. D., Amadieu, C., et al. (2019). Dietary n-3 long chain PUFA supplementation promotes a proresolving oxylipin profile in the brain. Brain Behav. Immun. 76, 17-27. doi: 10.1016/j.bbi.2018.07.025

Rey, C., Nadjar, A., Buaud, B., Vaysse, C., Aubert, A., Pallet, V., et al. (2016). Resolvin D1 and E1 promote resolution of inflammation in microglial cells in vitro. Brain Behav. Immun. 55, 249-259. doi: 10.1016/j.bbi.2015.12.013

Rey, C., Nadjar, A., Joffre, F., Amadieu, C., Aubert, A., Vaysse, C., et al. (2018). Maternal n-3 polyunsaturated fatty acid dietary supply modulates microglia lipid content in the offspring. Prostaglandins Leukot. Essent. Fatty Acids 133, 1-7. doi: 10.1016/j.plefa.2018.04.003

Rosenberger, T. A., Villacreses, N. E., Hovda, J. T., Bosetti, F., Weerasinghe, G., Wine, R. N., et al. (2004). Rat brain arachidonic acid metabolism is increased by a 6 -day intracerebral ventricular infusion of bacterial lipopolysaccharide. J. Neurochem. 88, 1168-1178. doi: 10.1046/j.1471-4159.2003.02246.x

Rosenthal, M. D., Patel, J., Staton, K., Martindale, R. G., Moore, F. A., and Upchurch, G. R. (2018). Can specialized pro-resolving mediators deliver benefit originally expected from fish oil? Curr. Gastroenterol. Rep. 20, 40. doi: 10.1007/s11894-018-0647-4

Rossi, S., Di Filippo, C., Gesualdo, C., Potenza, N., Russo, A., Trotta, M. C., et al. (2015). Protection from endotoxic uveitis by intravitreal Resolvin D1: involvement of lymphocytes, miRNAs, ubiquitin-proteasome, and M1/M2 macrophages. Mediators Inflamm. 2015, 149381. doi: 10.1155/2015/149381
Salinas, G., Rangasetty, U. C., Uretsky, B. F., and Birnbaum, Y. (2007). The cycloxygenase 2 (COX-2) story: it's time to explain, not inflame. J. Cardiovasc. Pharmacol. Ther. 12, 98-111. doi: 10.1177/1074248407301172

Schwab, J. M., Chiang, N., Arita, M., and Serhan, C. N. (2007). Resolvin E1 and protectin D1 activate inflammation-resolution programmes. Nature 447, 869874. doi: $10.1038 /$ nature 05877

Serhan, C. N. (2014). Pro-resolving lipid mediators are leads for resolution physiology. Nature 510, 92-101. doi: 10.1038/nature13479

Serhan, C. N. (2017a). Discovery of specialized pro-resolving mediators marks the dawn of resolution physiology and pharmacology. Mol. Aspects Med. 58, 1-11. doi: 10.1016/j.mam.2017.03.001

Serhan, C. N. (2017b). Treating inflammation and infection in the 21st century: new hints from decoding resolution mediators and mechanisms. FASEB J. 31, 1273-1288. doi: 10.1096/f.201601222R

Serhan, C. N., and Chiang, N. (2013). Resolution phase lipid mediators of inflammation: agonists of resolution. Curr. Opin. Pharmacol. 13, 632-640. doi: 10.1016/j.coph.2013.05.012

Serhan, C. N., Chiang, N., and Dalli, J. (2015). The resolution code of acute inflammation: novel pro-resolving lipid mediators in resolution. Semin. Immunol. 27, 200-215. doi: 10.1016/j.smim.2015.03.004

Serhan, C. N., Chiang, N., and Dalli, J. (2018). New pro-resolving n-3 mediators bridge resolution of infectious inflammation to tissue regeneration. Mol. Aspects Med. 64, 1-17. doi: 10.1016/j.mam.2017.08.002

Serhan, C. N., Clish, C. B., Brannon, J., Colgan, S. P., Chiang, N., and Gronert, K. (2000). Novel functional sets of lipid-derived mediators with antiinflammatory actions generated from omega-3 fatty acids via cyclooxygenase 2-nonsteroidal antiinflammatory drugs and transcellular processing. J. Exp. Med. 192, 11971204. doi: $10.1084 /$ jem.192.8.1197

Serhan, C. N., Hong, S., Gronert, K., Colgan, S. P., Devchand, P. R., Mirick, G., et al. (2002). Resolvins: a family of bioactive products of omega-3 fatty acid transformation circuits initiated by aspirin treatment that counter proinflammation signals. J. Exp. Med. 196, 1025-1037. doi: 10.1084/ jem. 20020760

Serhan, C. N., and Petasis, N. A. (2011). Resolvins and protectins in inflammation resolution. Chem. Rev. 111, 5922-5943. doi: 10.1021/cr100396c

Serhan, C. N., and Savill, J. (2005). Resolution of inflammation: the beginning programs the end. Nat. Immunol. 6, 1191-1197. doi: 10.1038/ni1276

Serhan, C. N., Yang, R., Martinod, K., Kasuga, K., Pillai, P. S., Porter, T. F., et al. (2009). Maresins: novel macrophage mediators with potent antiinflammatory and proresolving actions. J. Exp. Med. 206, 15-23. doi: 10.1084/jem.20081880

Shalini, S. M., Ho, C. F., Ng, Y. K., Tong, J. X., Ong, E. S., Herr, D. R., et al. (2017). Distribution of Alox 15 in the rat brain and its role in prefrontal cortical resolvin D1 formation and spatial working memory. Mol. Neurobiol. 1537-1550. doi: 10.1007/s12035-017-0413-x

Sheets, K. G., Jun, B., Zhou, Y., Zhu, M., Petasis, N. A., Gordon, W. C., et al. (2013). Microglial ramification and redistribution concomitant with the attenuation of choroidal neovascularization by neuroprotectin D1. Mol. Vis. 19, 1747-1759.

Shevalye, H., Yorek, M. S., Coppey, L. J., Holmes, A., Harper, M. M., Kardon, R. H., et al. (2015). Effect of enriching the diet with menhaden oil or daily treatment with resolvin D1 on neuropathy in a mouse model of type 2 diabetes. J. Neurophysiol. 114, 199-208. doi: 10.1152/jn.00224.2015

Shi, Z., Ren, H., Huang, Z., Peng, Y., He, B., Yao, X., et al. (2016). Fish oil prevents lipopolysaccharide-induced depressive-like behavior by inhibiting neuroinflammation. Mol. Neurobiol. 7327-7334. doi: 10.1007/s12035-016-0212-9

Siegert, E., Paul, F., Rothe, M., and Weylandt, K. H. (2017). The effect of omega-3 fatty acids on central nervous system remyelination in fat- 1 mice. $B M C$ Neurosci. 18, 19. doi: 10.1186/s12868-016-0312-5

Simopoulos, A. P. (2008). The importance of the omega-6/omega-3 fatty acid ratio in cardiovascular disease and other chronic diseases. Exp. Biol. Med. (Maywood) 233, 674-688. doi: 10.3181/0711-MR-311

Skarke, C., Alamuddin, N., Lawson, J. A., Li, X., Ferguson, J. F., Reilly, M. P., et al. (2015). Bioactive products formed in humans from fish oils. J. Lipid Res. 56, 1808-1820. doi: 10.1194/jlr.M060392

Skorve, J., Hilvo, M., Vihervaara, T., Burri, L., Bohov, P., Tillander, V., et al. (2015). Fish oil and krill oil differentially modify the liver and brain lipidome when fed to mice. Lipids Health Dis. 14, 88. doi: 10.1186/s12944-015-0086-2

Solito, E., and Sastre, M. (2012). Microglia function in Alzheimer's disease. Front. Pharmacol. 3, 14. doi: 10.3389/fphar.2012.00014 
Song, C., and Horrobin, D. (2004). Omega-3 fatty acid ethyl-eicosapentaenoate, but not soybean oil, attenuates memory impairment induced by central IL-1beta administration. J. Lipid Res. 45, 1112-1121. doi: 10.1194/jlr.M300526-JLR200

Song, C., Manku, M. S., and Horrobin, D. F. (2008). Long-chain polyunsaturated fatty acids modulate interleukin-lbeta-induced changes in behavior, monoaminergic neurotransmitters, and brain inflammation in rats. J. Nutr. 138, 954-963. doi: 10.1093/jn/138.5.954

Spanbroek, R., Hildner, M., Kohler, A., Muller, A., Zintl, F., Kuhn, H., et al. (2001). IL-4 determines eicosanoid formation in dendritic cells by down-regulation of 5-lipoxygenase and up-regulation of 15-lipoxygenase 1 expression. Proc. Natl. Acad. Sci. U. S. A. 98, 5152-5157. doi: 10.1073/pnas.091076998

Spite, M., Norling, L. V., Summers, L., Yang, R., Cooper, D., Petasis, N. A., et al. (2009). Resolvin D2 is a potent regulator of leukocytes and controls microbial sepsis. Nature 461, 1287-1291. doi: 10.1038/nature08541

Spite, M., and Serhan, C. N. (2010). Novel lipid mediators promote resolution of acute inflammation: impact of aspirin and statins. Circ. Res. 107, 1170-1184. doi: 10.1161/CIRCRESAHA.110.223883

Stewart, T. M., and Bowling, A. C. (2005). Polyunsaturated fatty acid supplementation in MS. Int. MS. J. 12, 88-93.

Sugimoto, M. A., Sousa, L. P., Pinho, V., Perretti, M., and Teixeira, M. M. (2016). Resolution of inflammation: what controls its onset? Front. Immunol. 7, 160. doi: $10.3389 /$ fimmu. 2016.00160

Sun, L., Xu, Y. W., Han, J., Liang, H., Wang, N., and Cheng, Y. (2015). 12/15-Lipoxygenase metabolites of arachidonic acid activate PPARgamma: a possible neuroprotective effect in ischemic brain. J. Lipid Res. 56, 502-514. doi: 10.1194/jlr.M053058

Sun, W., Wang, Z. P., Gui, P., Xia, W., Xia, Z., Zhang, X. C., et al. (2014). Endogenous expression pattern of resolvin D1 in a rat model of self-resolution of lipopolysaccharide-induced acute respiratory distress syndrome and inflammation. Int. Immunopharmacol. 23, 247-253. doi: 10.1016/j.intimp.2014.09.001

Sun, Y. P., Oh, S. F., Uddin, J., Yang, R., Gotlinger, K., Campbell, E., et al. (2007). Resolvin D1 and its aspirin-triggered 17R epimer. Stereochemical assignments, anti-inflammatory properties, and enzymatic inactivation. J. Biol. Chem. 282, 9323-9334. doi: 10.1074/jbc.M609212200

Taha, A. Y., Blanchard, H. C., Cheon, Y., Ramadan, E., Chen, M., Chang, L., et al. (2017). Dietary linoleic acid lowering reduces lipopolysaccharide-induced increase in brain arachidonic acid metabolism. Mol. Neurobiol. 54, 4303-4315. doi: 10.1007/s12035-016-9968-1

Taha, A. Y., Hennebelle, M., Yang, J., Zamora, D., Rapoport, S. I., Hammock, B. D., et al. (2016). Regulation of rat plasma and cerebral cortex oxylipin concentrations with increasing levels of dietary linoleic acid. Prostaglandins Leukot. Essent. Fatty Acids. doi: 10.1016/j.plefa.2016.05.004

Terrando, N., Gomez-Galan, M., Yang, T., Carlstrom, M., Gustavsson, D., Harding, R. E., et al. (2013). Aspirin-triggered resolvin D1 prevents surgeryinduced cognitive decline. FASEB J. 27, 3564-3571. doi: 10.1096/ff.13-230276

Thomazeau, A., Bosch-Bouju, C., Manzoni, O., and Layé, S. (2017). Nutritional n-3 PUFA deficiency abolishes endocannabinoid gating of hippocampal long-term potentiation. Cereb. Cortex 27, 2571-2579. doi: 10.1093/cercor/ bhw052

Tian, Y., Zhang, Y., Zhang, R., Qiao, S., and Fan, J. (2015). Resolvin D2 recovers neural injury by suppressing inflammatory mediators expression in lipopolysaccharide-induced Parkinson's disease rat model. Biochem. Biophys. Res. Commun. 460, 799-805. doi: 10.1016/j.bbrc.2015.03.109

Titos, E., Rius, B., Gonzalez-Periz, A., Lopez-Vicario, C., Moran-Salvador, E., Martinez-Clemente, M., et al. (2011). Resolvin D1 and its precursor docosahexaenoic acid promote resolution of adipose tissue inflammation by eliciting macrophage polarization toward an M2-like phenotype. J. Immunol. 187, 5408-5418. doi: 10.4049/jimmunol.1100225

Tremblay, M. E., Zhang, I., Bisht, K., Savage, J. C., Lecours, C., Parent, M., et al. (2016). Remodeling of lipid bodies by docosahexaenoic acid in activated microglial cells. J. Neuroinflamm. 13, 116. doi: 10.1186/s12974-016-0580-0

Trépanier, M.-O., Hopperton, K. E., Giuliano, V., Masoodi, M., and Bazinet, R. P. (2018). Increased brain docosahexaenoic acid has no effect on the resolution of neuroinflammation following intracerebroventricular lipopolysaccharide injection. Neurochem. Int. 118, 115-126. doi: 10.1016/j.neuint.2018.05.010

Wang, D., Liu, Y., Chen, L., Li, P., Qu, Y., and Zhu, Y. (2017). Key role of 15-LO/15HETE in angiogenesis and functional recovery in later stages of post-stroke mice. Sci. Rep. 7, 46698. doi: 10.1038/srep46698
Wang, R. X., and Colgan, S. P. (2017). Special pro-resolving mediator (SPM) actions in regulating gastro-intestinal inflammation and gut mucosal immune responses. Mol. Aspects Med. 58, 93-101. doi: 10.1016/j.mam.2017.02.002

Wang, X., Zhu, M., Hjorth, E., Cortes-Toro, V., Eyjolfsdottir, H., Graff, C., et al. (2015). Resolution of inflammation is altered in Alzheimer's disease. Alzheimers Dement. 11, 40-50 e1-2. doi: 10.1016/j.jalz.2013.12.024

Wang, Y., Botolin, D., Christian, B., Busik, J., Xu, J., and Jump, D. B. (2005). Tissuespecific, nutritional, and developmental regulation of rat fatty acid elongases. J. Lipid Res. 46, 706-715. doi: 10.1194/jlr.M400335-JLR200

Wang, Y. P., Wu, Y., Li, L. Y., Zheng, J., Liu, R. G., Zhou, J. P., et al. (2011). Aspirintriggered lipoxin A4 attenuates LPS-induced pro-inflammatory responses by inhibiting activation of NF-kappaB and MAPKs in BV-2 microglial cells. J. Neuroinflamm. 8, 95. doi: 10.1186/1742-2094-8-95

Weinstock-Guttman, B., Baier, M., Park, Y., Feichter, J., Lee-Kwen, P., Gallagher, E., et al. (2005). Low fat dietary intervention with omega-3 fatty acid supplementation in multiple sclerosis patients. Prostaglandins Leukot. Essent. Fatty Acids 73, 397-404. doi: 10.1016/j.plefa.2005.05.024

Weiser, M. J., Mucha, B., Denheyer, H., Atkinson, D., Schanz, N., Vassiliou, E., et al. (2016). Dietary docosahexaenoic acid alleviates autistic-like behaviors resulting from maternal immune activation in mice. Prostaglandins Leukot. Essent. Fatty Acids 106, 27-37. doi: 10.1016/j.plefa.2015.10.005

Winkler, J. W., Orr, S. K., Dalli, J., Cheng, C. Y., Sanger, J. M., Chiang, N., et al. (2016). Resolvin D4 stereoassignment and its novel actions in host protection and bacterial clearance. Sci. Rep. 6, 18972. doi: 10.1038/srep 18972

Xian, W., Li, T., Li, L., Hu, L., and Cao, J. (2019). Maresin 1 attenuates the inflammatory response and mitochondrial damage in mice with cerebral ischemia/reperfusion in a SIRT1-dependent manner. Brain Res. 83-90. doi: 10.1016/j.brainres.2019.01.013

Xian, W., Wu, Y., Xiong, W., Li, L., Li, T., Pan, S., et al. (2016). The pro-resolving lipid mediator Maresin 1 protects against cerebral ischemia/reperfusion injury by attenuating the pro-inflammatory response. Biochem. Biophys. Res. Commun. 472, 175-181. doi: 10.1016/j.bbrc.2016.02.090

Xiao, Y., Huang, Y., and Chen, Z. Y. (2005). Distribution, depletion and recovery of docosahexaenoic acid are region-specific in rat brain. Br. J. Nutr. 94, 544-550. doi: 10.1079/BJN20051539

Xu, Z. Z., Berta, T., and Ji, R. R. (2013). Resolvin E1 inhibits neuropathic pain and spinal cord microglial activation following peripheral nerve injury. J. Neuroimmune Pharmacol. 8, 37-41. doi: 10.1007/s11481-012-9394-8

Xu, Z. Z., Zhang, L., Liu, T., Park, J. Y., Berta, T., Yang, R., et al. (2010). Resolvins $\mathrm{RvE} 1$ and RvD1 attenuate inflammatory pain via central and peripheral actions. Nat. Med. 16, 592-7, lp following 597. doi: 10.1038/nm.2123

Yao, C., Zhang, J., Chen, F., and Lin, Y. (2013). Neuroprotectin D1 attenuates brain damage induced by transient middle cerebral artery occlusion in rats through TRPC6/CREB pathways. Mol. Med. Rep. 8, 543-550. doi: 10.3892/mmr.2013.1543

Yigitkanli, K., Zheng, Y., Pekcec, A., Lo, E. H., and van Leyen, K. (2017). Increased 12/15-lipoxygenase leads to widespread brain injury following global cerebral ischemia. Transl. Stroke Res. 8, 194-202. doi: 10.1007/s12975-016-0509-z

Yirmiya, R., and Goshen, I. (2011). Immune modulation of learning, memory, neural plasticity and neurogenesis. Brain Behav. Immun. 25, 181-213. doi: 10.1016/j. bbi.2010.10.015

Zhu, M., Wang, X., Hjorth, E., Colas, R. A., Schroeder, L., Granholm, A. C., et al. (2016). Pro-resolving lipid mediators improve neuronal survival and increase abeta42 phagocytosis. Mol. Neurobiol. 53, 2733-2749. doi: 10.1007/s12035-015-9544-0

Zimmer, L., Delpal, S., Guilloteau, D., Aioun, J., Durand, G., and Chalon, S. (2000). Chronic n-3 polyunsaturated fatty acid deficiency alters dopamine vesicle density in the rat frontal cortex. Neurosci. Lett. 284, 25-28. doi: 10.1016/ S0304-3940(00)00950-2

Conflict of Interest Statement: The authors declare that the research was conducted in the absence of any commercial or financial relationships that could be construed as a potential conflict of interest.

Copyright (๑ 2019 Joffre, Rey and Layé. This is an open-access article distributed under the terms of the Creative Commons Attribution License (CC BY). The use, distribution or reproduction in other forums is permitted, provided the original author(s) and the copyright owner(s) are credited and that the original publication in this journal is cited, in accordance with accepted academic practice. No use, distribution or reproduction is permitted which does not comply with these terms. 